\title{
A MYC-Driven Plasma Polyamine Signature for Early Detection of Ovarian Cancer
}

\author{
Johannes F. Fahrmann ${ }^{1,+}$, Ehsan Irajizad ${ }^{2,+}$, Makoto Kobayashi ${ }^{1}$, Jody Vykoukal ${ }^{1}$, Jennifer B. Dennison ${ }^{1}$, \\ Eunice Murage ${ }^{1}$, Ranran Wu ${ }^{1}{ }^{D}$, James P. Long ${ }^{2}$, Kim-Anh Do ${ }^{2}$, Joseph Celestino ${ }^{3}$, Karen H. Lu ${ }^{3}$, Zhen Lu ${ }^{3} \mathbb{D}$, \\ Robert C. Bast Jr. ${ }^{4}$ and Samir Hanash ${ }^{1, *}$
}

\section{check for} updates

Citation: Fahrmann, J.F.; Irajizad, E.; Kobayashi, M.; Vykoukal, J.; Dennison, J.B.; Murage, E.; Wu, R.; Long, J.P.; Do, K.-A.; Celestino, J.; et al. A MYC-Driven Plasma Polyamine Signature for Early Detection of Ovarian Cancer. Cancers 2021, 13, 913. https://doi.org/ 10.3390/cancers13040913

Academic Editor: Daniela M. Dinulescu

Received: 12 January 2021

Accepted: 2 February 2021

Published: 22 February 2021

Publisher's Note: MDPI stays neutral with regard to jurisdictional claims in published maps and institutional affiliations.

Copyright: (c) 2021 by the authors. Licensee MDPI, Basel, Switzerland. This article is an open access article distributed under the terms and conditions of the Creative Commons Attribution (CC BY) license (https:// creativecommons.org/licenses/by/ $4.0 /)$.
1 Department of Clinical Cancer Prevention, The University of Texas M. D. Anderson Cancer Center, Houston, TX 77030, USA; jffahrmann@mdanderson.org (J.F.F.); dm11018s@st.kitasato-u.ac.jp (M.K.); jvykouka@mdanderson.org (J.V.); jbdennis@mdanderson.org (J.B.D.); ENMurage@mdanderson.org (E.M.); RWu2@mdanderson.org (R.W.)

2 Department of Biostatistics, The University of Texas M. D. Anderson Cancer Center, Houston, TX 77030, USA; EIrajizad@mdanderson.org (E.I.); JPLong@mdanderson.org (J.P.L.); kimdo@mdanderson.org (K.-A.D.)

3 Department of Gynecological Oncology and Reproductive Medicine, The University of Texas M. D. Anderson Cancer Center, Houston, TX 77030, USA; jcelesti@mdanderson.org (J.C.); khlu@mdanderson.org (K.H.L.); zlu@mdanderson.org (Z.L.)

4 Department of Experimental Therapeutics, The University of Texas M. D. Anderson Cancer Center, Houston, TX 77030, USA; rbast@mdanderson.org

* Correspondence: shanash@mdanderson.org

+ Contributed equally to this work.

Simple Summary: There is a need for additional marker(s) to detect early-stage ovarian cancer that would augment the performance of CA125. Herein, we report a polyamine signature that is detected in the blood and that has value for detecting ovarian cancers at an early stage. The polyamine signature was able to complement CA125 in identifying more ovarian cancer cases that would have been missed by CA125 alone. Our validation of a polyamine signature provides compelling evidence for the value of blood polyamine metabolites as markers for ovarian cancer detection.

Abstract: MYC is an oncogenic driver in the pathogenesis of ovarian cancer. We previously demonstrated that MYC regulates polyamine metabolism in triple-negative breast cancer (TNBC) and that a plasma polyamine signature is associated with TNBC development and progression. We hypothesized that a similar plasma polyamine signature may associate with ovarian cancer (OvCa) development. Using mass spectrometry, four polyamines were quantified in plasma from 116 OvCa cases and 143 controls (71 healthy controls +72 subjects with benign pelvic masses) (Test Set). Findings were validated in an independent plasma set from 61 early-stage OvCa cases and 71 healthy controls (Validation Set). Complementarity of polyamines with CA125 was also evaluated. Receiver operating characteristic area under the curve (AUC) of individual polyamines for distinguishing cases from healthy controls ranged from $0.74-0.88$. A polyamine signature consisting of diacetylspermine + $\mathrm{N}$-(3-acetamidopropyl)pyrrolidin-2-one in combination with CA125 developed in the Test Set yielded improvement in sensitivity at $>99 \%$ specificity relative to CA125 alone (73.7\% vs $62.2 \%$; McNemar exact test 2-sided P: 0.019 ) in the validation set and captured $30.4 \%$ of cases that were missed with CA125 alone. Our findings reveal a MYC-driven plasma polyamine signature associated with OvCa that complemented CA125 in detecting early-stage ovarian cancer.

Keywords: blood-based biomarkers; polyamines; ovarian cancer; early detection

\section{Introduction}

Currently, over $70 \%$ of patients with ovarian cancer present with advanced-stage (III-IV) disease, with dismal 5-year survival rates of less than $30 \%$. Survival rates up to 70-90\% can, however, be achieved with conventional surgery and chemotherapy, when 
disease is localized to the ovary (stage I) or pelvis (Stage II). [1,2] To-date, CA125 is the most investigated ovarian cancer early detection marker. [3] Neither CA125 nor transvaginal sonography (TVS) alone has adequate sensitivity or specificity for early detection. A twostage strategy whereby rising CA125 prompts TVS in a limited fraction of women screened can achieve adequate specificity, but the sensitivity of CA125 is limited. [4] Moreover, only $80 \%$ of epithelial ovarian cancers express significant levels of CA125. [5] Thus, there is a need for an additional marker(s) to detect early-stage disease that would complement the performance of CA125.

Ovarian cancer and triple-negative breast cancer (TNBC) share common genomic features including MYC copy-number amplification. [6] MYC is an oncogenic driver in the pathogenesis of ovarian cancer. [7-9] We have previously demonstrated that MYC regulates the transcription of several polyamine metabolizing enzymes (PMEs) in triple negative breast cancer and that a plasma polyamine signature is associated with TNBC development and progression. [10] Herein, we tested whether a plasma polyamine signature would similarly be associated with ovarian cancer. We also evaluated whether polyamines, in combination with CA125, would improve classification performance compared to CA125 alone.

\section{Materials and Methods}

\subsection{Blood Samples}

EDTA-plasma samples were obtained from the Normal Risk Ovarian Cancer Screening Study (NROSS) and stored at the MD Anderson Gynecologic Cancer Bank. All biospecimen were processed at a central site using a standardized protocol; EDTA-plasmas were stored in $-80^{\circ} \mathrm{C}$ until use. Ethical approval was obtained for these samples from the appropriate institutional review boards/ethic committees at MD Anderson and collaborating institutions under IRB protocol LAB04-0687. All participants had consent for the use of samples in ethically approved secondary studies.

Randomly selected healthy control plasmas were obtained from the NROSS cohort. Over the last two decades, the NROSS trial has involved 6379 postmenopausal women over the age of 50 at average risk for developing ovarian cancer and who have been followed with annual CA125 measurements and who have been referred for transvaginal ultrasound and gynecological evaluation if CA125 values increase from each individual's baseline as judged by the Risk of Ovarian Cancer Algorithm (ROCA). Healthy controls were at least 12 months postmenopausal, between the ages of 50-75 and followed for a minimum of 7 years to ensure cancer-free status; cancer-free status was based on an annual self-reported questionnaire.

Plasma samples from treatment-naïve cases and control subjects presenting with benign pelvic masses were drawn from the MD Anderson Gynecologic Cancer Bank. Cases were randomly selected and not prioritized based on CA125 values.

Initial testing was performed using plasmas from 41 early stage (I-II) cases, 75 latestage (III-IV) cases, 71 healthy controls and 72 patients with benign pelvic masses. The validation set consisted of an independent set of plasmas from 61 early-stage cases and 71 healthy controls. Subject characteristics are provided in Table 1. Detailed information on the benign pelvic masses as well as histological subtype of ovarian cancers amongst cases is provided in Table A1 in the Appendix A. 
Table 1. Patient characteristics for the Test Set and Validation Set.

\begin{tabular}{|c|c|c|c|c|c|}
\hline \multirow[t]{2}{*}{$\begin{array}{l}\text { Patient Characteristics for } \\
\text { Specimen Sets }\end{array}$} & \multicolumn{3}{|c|}{ Test Set } & \multicolumn{2}{|c|}{ Validation Set } \\
\hline & Cases & Controls \#1 + & Controls \#2 $\ddagger$ & Cases & Controls \#1 † \\
\hline Number of Subjects & 116 & 71 & 72 & 61 & 71 \\
\hline Age (mean $+/-$ stdev $)$ & $58+/-13$ & $69+/-7$ & $56+/-13$ & $57+/-15$ & $65+/-9$ \\
\hline $\begin{array}{l}\text { CA125 }(\mathrm{u} / \mathrm{mL}) \text {, median }(25 \text { th } / 75 \text { th } \\
\text { percentile) }\end{array}$ & $\begin{array}{c}224 \\
(87 / 561)\end{array}$ & $12(9 / 16)$ & $23(13 / 59)$ & $102(45 / 321)$ & $11(8 / 17)$ \\
\hline \multicolumn{6}{|l|}{ Serous } \\
\hline Stage I, N (\%) & $11(9.5)$ & - & - & $13(21.3)$ & - \\
\hline Stage II, N (\%) & $5(4.3)$ & - & - & $15(24.6)$ & - \\
\hline Stage III, N (\%) & $64(55.2)$ & - & - & - & - \\
\hline Stage IV, N (\%) & $11(9.5)$ & - & - & - & - \\
\hline \multicolumn{6}{|l|}{ Non-Serous } \\
\hline \multicolumn{6}{|l|}{ Endometrioid } \\
\hline Stage I, N (\%) & $10(8.6)$ & - & - & $16(26.2)$ & - \\
\hline Stage II, N (\%) & $2(1.7)$ & - & - & $6(9.8)$ & - \\
\hline \multicolumn{6}{|l|}{ Mucinous } \\
\hline Stage I, N (\%) & $3(2.6)$ & - & - & $6(9.8)$ & - \\
\hline Stage II, N (\%) & $1(0.9)$ & - & - & & \\
\hline \multicolumn{6}{|l|}{ Clear Cell Carcinoma } \\
\hline Stage I, N (\%) & $6(5.2)$ & - & - & $3(4.9)$ & - \\
\hline Stage II, N (\%) & $2(1.7)$ & - & - & $1(1.6)$ & - \\
\hline \multicolumn{6}{|l|}{ Other } \\
\hline Transitional cell carcinoma (Stage I) & $1(0.9)$ & - & - & $1(1.6)$ & - \\
\hline
\end{tabular}

† Controls \#1- Healthy Controls. ¥ Controls \#2- Subjects with benign pelvic masses.

\subsection{Metabolomics Analysis}

Detailed information is provided in the Appendix A. Semi-quantitative measurement of plasma polyamines was conducted on a Waters Acquity ${ }^{\mathrm{TM}}$ UPLC system with 2D column regeneration (I-class and H-class) coupled to a Xevo G2-XS quadrupole time-offlight (qTOF) mass spectrometer. Chromatographic separation was performed using HILIC (Acquity ${ }^{\mathrm{TM}} \mathrm{UPLC}$ BEH amide, $100 \AA$, $1.7 \mu \mathrm{m} 2.1 \times 100 \mathrm{~mm}$ ) and C18 (Acquity ${ }^{\mathrm{TM}}$ UPLC HSS T3, $100 \AA, 1.8 \mu \mathrm{m}, 2.1 \times 100 \mathrm{~mm}$ ) columns at $45^{\circ} \mathrm{C}$. Mass spectrometry data were acquired in sensitivity, positive electrospray ionization mode. Acquisition was carried out with instrument auto-gain control to optimize sensitivity during sample acquisition; data processing was performed as previously described [10,11].

Four polyamines (diacetylspermine (DAS), acetylspermidine (AcSpmd), diacetylspermidine (DiAcspmd), and N-(3-acetamidopropyl)pyrrolidin-2-one (N3AP)) were detected and quantified in plasmas of cases and controls (Table A2 in the Appendix A). Coefficient of variation $(\mathrm{CV})$ values for the measured polyamines in quality controls are provided in Table A3 in the Appendix A. On average, CV values for measured polyamines in quality control samples were below $13 \%$.

\subsection{Measurement of CA125 Levels}

Automated immunoassay kits for determining the concertation of CA125 antigen were purchased from Roche Diagnostics USA (Indianapolis, IN, USA).

\subsection{Statistical Analyses}

For two-class comparisons, statistical significance was determined using the Wilcoxon rank sum test. Statistical significance was determined at $p$-values $<0.05$. Receiver operating characteristic curves were generated using $R$ ( $R$ version 3.6.0). The $95 \%$ confidence intervals presented for the individual performance of each biomarker were based on the bootstrap procedure in which we re-sampled with replacement separately for the controls and the diseased 1000 bootstrap samples. To identify the optimal combination of markers 
amongst CA125 and four other polyamines, we implemented Lasso regression. [12] Tenfold cross-validation on the training dataset with AUC as the measurement of classification performance was incorporated to find the best tuning parameters $(\lambda)$. This parameter yielded CA125, DAS, and N3AP as the best combination of biomarkers; a biomarker panel using CA125, DAS, and N3AP were subsequently derived using a logistic regression model. The estimated AUC of the proposed metabolite panel was derived by using the empirical ROC estimator of the linear combination corresponding to the aforementioned model.

Confusion matrices were utilized to describe the classification model of the 3-marker panel or CA125 alone at a 99\% specificity cutoff. Rows of the matrix display the predicted classes (case or control) whereas columns represent the actual classes (case or control).

To test whether the 3-marker panel yielded statistically significant classifier improvements over CA125, the McNemar exact test was applied to compare two binomial proportions for patients with two different biomarker scores [13]. Herein, a $2 \times 2$ table was generated wherein the first cell represents the number of patients that both markers predict correctly (a), the second one represents the number of patients correctly identified by CA125 and misclassified by the 3-marker panel (b), the third one represents the number of patients misclassified by CA125 but correctly identified by the 3-marker panel (c) and the last cell represents the number of patients misclassified by both markers (d). Therefore, the null and alternative hypothesize are as follows:

$$
\begin{aligned}
& \text { H_0: } P_{-} b=P_{-} c \\
& \text { H_a: } P \_b<P \_c
\end{aligned}
$$

Herein, $\mathrm{P} \_$i denotes the probability of occurrence in cell i. An exact binomial test was used to achieve $p$-value [14].

All statistical tests were two-sided unless specified otherwise.

\section{Results}

\subsection{Polyamine Levels in Plasma of Ovarian Cancer Patients and Model Development}

To determine whether a polyamine signature is associated with ovarian cancer, we screened polyamine levels in plasma from 116 OvCa patients (41 early stage +75 late stage, 91 serous, 25 non-serous) and 71 healthy controls (Test Set) using ultrahigh performance liquid chromatography mass spectrometry (Table 1). We additionally evaluated the levels of polyamines in plasma from 72 patients presenting with diverse benign conditions to determine the specificity of polyamines for OvCa (Table 1; detailed information is provided Table A1).

A total of four polyamines (DAS, AcSpmd, DiAcspmd, and N3AP) were detected and quantified in plasmas of cases and controls (Table A2 in the Appendix A). AUCs of individual polyamines for distinguishing OvCa from healthy controls ranged from $0.74-0.88$ (Figure 1A; Table A4 in the Appendix A). Measured polyamines were generally positively correlated to each other (Figure A1 in the Appendix A). Of the measured polyamines, DAS exhibited the highest classification performance for distinguishing ovarian cancer cases from healthy controls (AUC: 0.88 (95\% C.I., 0.84-0.93)) or patients with benign pelvic masses (AUC: 0.78 (95\% C.I., 0.72-0.85)) (Figure 1A,B; Table A4 in the Appendix A). AUCs of DAS for distinguishing all serous cases from healthy controls or subjects with benign pelvic masses were 0.90 and 0.80 , respectively (Table A5 in the Appendix A). When considering only early-stage serous cases, DAS yielded AUCs of 0.81 and 0.70 in comparison to healthy controls or subjects with benign pelvic masses, respectively (Table A5 in the Appendix A). AUCs of DAS for distinguishing non-serous OvCa cases from healthy controls or subjects with benign pelvic masses or healthy controls were 0.83 and 0.71 , respectively (Table A5 and Figure A2 in the Appendix A). 


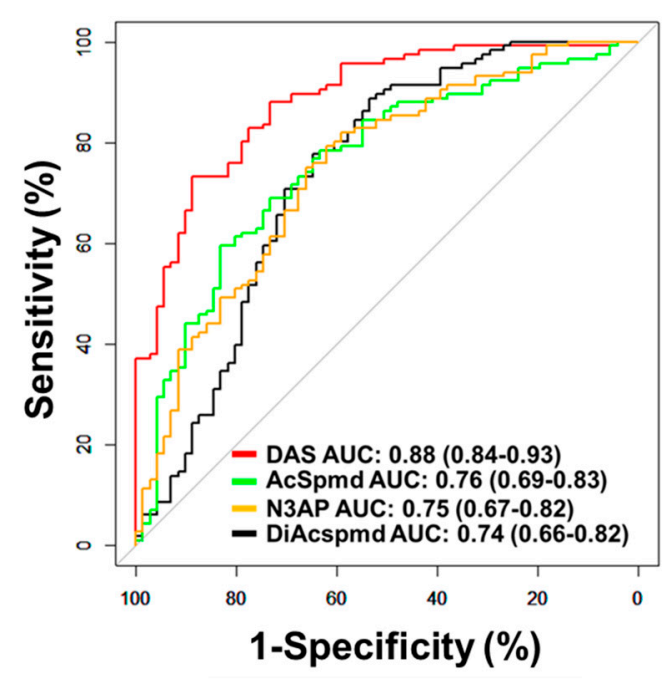

(A)

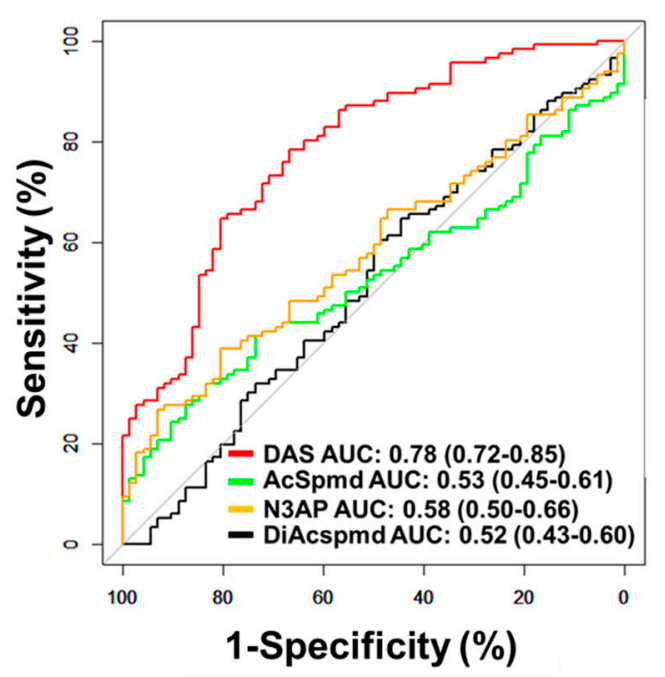

(B)

Figure 1. Classification performances of plasma polyamines in the Test Set. $(\mathbf{A}, \mathbf{B})$ Area under the curve (AUC) of DAS for delineating all cases $(n=116)$ from healthy controls $(n=71)$ (A) or patients with benign pelvic masses $(n=72)(B)$.

Using logistic regression models, we determined whether the combination of polyamines plus CA125 would yield improved classification performance in differentiating early-stage OvCa cases from controls (healthy subjects + subjects with benign pelvic masses) when compared to CA125 alone. The combination of plasma DAS + N3AP + CA125 was identified as the best panel with an AUC point estimate of 0.84 (95\% C.I., 0.77-0.92) (Figure 2A). Given the low prevalence of ovarian cancer (11.4 in every 100,000 people), a screening test must achieve high sensitivity at high specificity to avoid unacceptable levels of false-positive results. Therefore, we evaluated the sensitivity of the 3-marker panel (DAS + N3AP + CA125) in comparison to CA125 alone at corresponding specificities of $99 \%$, 98.5\% and 97\% (Table A6 in the Appendix A). Compared to CA125 alone, the 3-marker panel yielded statistically significantly improved sensitivity at $99 \%$ and $98.5 \%$ specificity (1-sided McNemar Exact test P: 0.006 and 0.04, respectively) (Table A6 in the Appendix A). A confusion matrix describing the performance of the classification model corresponding to the 3-marker panel and CA125 alone at 99\% specificity illustrates that the 3-marker panel correctly identified 19 out of 44 early-stage OvCa cases ( $46.3 \%$ sensitivity) whereas CA125 alone correctly identified 10 out of early-stage 41 OvCa cases (24.3\% sensitivity) (1-sided McNemar exact test P: 0.006) (Figure 2B,C).

In our study, correlation analyses between DAS, N3AP, and CA125 levels (which comprise the 3-marker panel) with ages amongst healthy controls were non-statistically significant (data not shown). Age-adjusted ROC analyses revealed that the 3-marker panel of DAS + N3AP + CA125 (age-adjusted AUC: 0.80 (95\% CI: 0.71-0.88)) yielded improved classifier performance as compared to CA125 alone (age-adjusted AUC: 0.70 (95\% CI: 0.58-0.82), Delong's comparison of AUCs 1-sided P: 0.002). These findings imply that age is not a confounder in the context of the current study. 
A
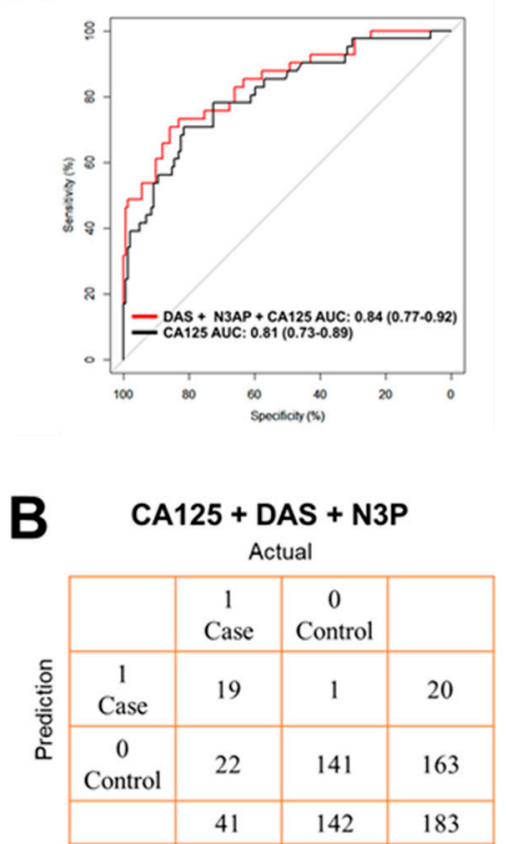

C

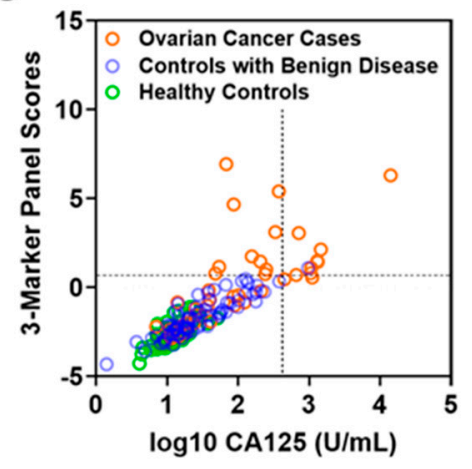

CA125 Only

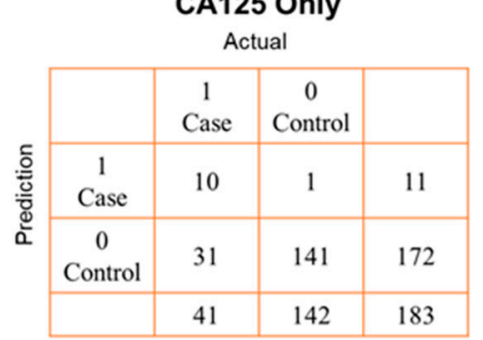

\section{McNemar exact test 1-sided P: 0.006}

Figure 2. Classification performance of the 3-marker panel and CA125 in the Test Set. (A) Area under the curve for the 3-marker panel consisting of DAS + N3AP + CA125, and CA125 only. (B) Confusion matrix describing the performance of the classification model corresponding to the 3-marker panel and CA125 alone at $99 \%$ specificity. Statistical significance was determined by 1-sided McNemar exact test. (C) Scatter plot illustrating the distribution of the 3-marker panel scores (Y-axis) and $\log 10$ CA125 values (X-axis). Broken lines represent $99 \%$ specificity cutoffs.

\subsection{Model Validation in an Independent Cohort of Early Stage Ovarian Cancer Patients}

Further validation of the polyamine metabolites individually and the fixed 3-marker panel consisting of DAS + N3AP + CA125 was performed in an independent set of plasma samples consisting of 61 early-stage OvCa cases (serous $=28$, non-serous $=33$ ) and 71 healthy controls (Validation Set; Table 1). AUCs for individual polyamine metabolites ranged from 0.57-0.84 (Figure 3). Plasma DAS exhibited the highest AUC point estimate for delineating OvCa cases from controls (AUC: 0.84 (95\% C.I., 0.77-0.91)) (Figure 3). Classification performance of plasma DAS in distinguishing serous $(n=28)$ and non-serous cases $(n=33)$ from healthy controls was 0.84 (95\% C.I., 0.75-0.93) and 0.84 (95\% C.I., 0.75-0.92), respectively (Table A7 and Figure A3 in the Appendix A).

In the validation set, the fixed 3-marker panel yielded an AUC of 0.95 (95\% C.I., 0.92-0.99) whereas CA125 yielded an AUC of 0.96 (95\% C.I., 0.94-0.99). Sensitivity of the 3-marker panel using fixed beta-coefficients derived from the test set at corresponding specificities of $>99 \%, 98.5 \%$, and $97 \%$ for the validation set were $73.7,78.6$, and 83.6, respectively (Table A6 in the Appendix A). Compared to CA125 alone, the 3-marker panel yielded statistically significantly improved sensitivity at $>99 \%$ specificity (3-marker panel sensitivity: 73.7\%, CA125 sensitivity: 62.2\%, 1-sided McNemar exact test P: 0.02) (Table A6 in the Appendix A). A confusion matrix describing the performance of the classification model corresponding to the 3-marker panel and CA125 alone at $>99 \%$ specificity shows that the 3-marker panel correctly identified 45 out of 61 early-stage OvCa cases in the validation set whereas CA125 alone correctly identified 38 out of 61 early-stage OvCa cases, which corresponds to capturing $30.4 \%$ of cases missed by CA125 alone (Figure 4A,B). 


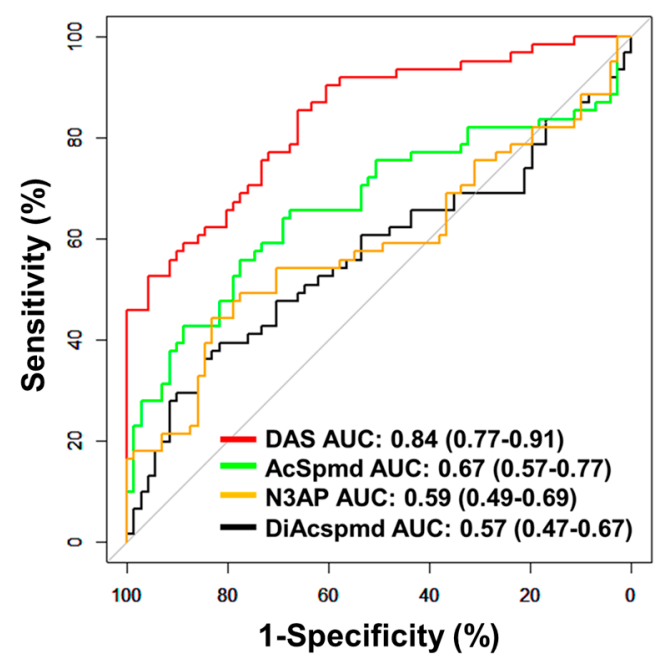

Figure 3. Classification performances of plasma polyamines in the validation set. The area under the curve (AUC) of individual polyamines for delineating all cases $(n=61)$ from healthy controls $(n=71)$.

A CA125 cutoff value of $35 \mathrm{U} / \mathrm{mL}$ is considered the upper limit of "normal" [15]. In the validation set, a cutoff value of $35 \mathrm{U} / \mathrm{mL}$ captured 53 out of 61 cases $(86.9 \%$ sensitivity) with 2 false-positives ( $97.2 \%$ specificity). If considering cases "negative" for CA125 (defined as $\leq 35 \mathrm{U} / \mathrm{mL}$ ), the fixed 3-marker panel identifies an additional 2 of the 8 early-stage cases ( $25.0 \%$ sensitivity) without any additional false-positives (Figure A4 in the Appendix A). Notably, these two additional cases identified by the 3-marker panel were stage I high-grade serous carcinomas.

\section{A}

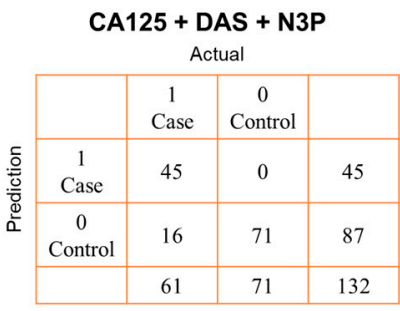

McNemar exact test 1-sided P: 0.0

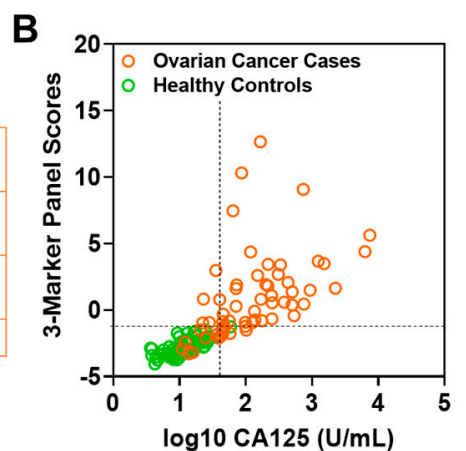

Figure 4. Classification performance of the 3-marker panel and CA125 in the validation set. (A) Confusion matrix describing the performance of the classification model corresponding to the 3-marker panel and CA125 alone at 99\% specificity. Statistical significance was determined by 1-sided McNemar exact test. (B) Scatter plot illustrating the distribution of the 3-marker panel scores (Y-axis) and $\log 10$ CA125 values (X-axis). Broken lines represent $>99 \%$ specificity cutoffs.

\section{Discussion}

We demonstrated and validated that polyamines are statistically significantly elevated in plasmas of ovarian cancer cases in comparison to controls using two independent case-control cohorts. Of the measured polyamines, DAS exhibited the highest AUC for distinguishing cases from healthy controls or subjects presenting with benign pelvic masses. Importantly, we demonstrated that a 3-marker panel consisting of DAS + N3AP + CA125 yielded improved sensitivity at $>99 \%$ specificity in comparison to CA125 only, resulting in capturing early-stage cases that were missed by CA125 alone in the validation set. Classifier performance of polyamines was higher in late-stage compared to early-stage cases, implicating that the polyamine levels reflect disease burden. Further, polyamines were elevated in both serous and non-serous cases. Recent reports indicated marked heterogeneity in clinical outcomes of ovarian cancer histological subtypes 
with non-serous subtypes exhibiting survival rates similar to or worse than that of highgrade serous carcinomas [16]. A blood test that can broadly identify ovarian cancers is, therefore, desirable.

There are potential limitations inherent to the available cohorts used in the study. Healthy controls tended to be older than cases. However, the 3-marker panel retained improved classifier performance compared to CA125 alone when adjusting AUCs for age, indicating that age is not a confounder variable in our analyses. Our study has a moderate sample size of early-stage OvCa cases. We emphasize that polyamines, DAS, in particular, yielded a good classifier performance for distinguishing early-stage OvCa cases from healthy controls in both the test and validation set. The performance of polyamine markers was reduced when considering subjects with benign pelvic masses suggestive that the presence of benign conditions may result in potential false-positives. Nevertheless, our findings demonstrated that polyamines, particularly DAS, were capable of distinguishing early-stage OvCa from subjects presenting with benign pelvic masses.

Integrated genome analysis has reported that the $M Y C$ gene is amplified in $30-40 \%$ of human ovarian tumors [8,17-19]. In addition to MYC, copy-number amplification and/or overexpression of MYCL1 and MYCN have also been reported in ovarian tumors [20-22]. We and others have demonstrated that the polyamine metabolizing enzymes ODC1, SRM and SMS are transcriptionally regulated by MYC [10,23-25] thereby providing a link between our polyamine signature and regulation via oncogenic MYC. In the context of our study, information regarding MYC status in tumors of subjects for which plasma polyamine levels were analyzed was not available thus precluding correlative analyses.

Prior studies have examined polyamine levels in urine and in one study, urine polyamines were found to be elevated among subjects with ovarian cancer. Similar to our findings, DAS exhibited the best classification performance for delineating ovarian cancer cases from individuals with benign disease and was found to be associated with disease progression [26].

In conclusion, we have identified an MYC-driven polyamine signature that reflects the early pathogenesis of ovarian cancer. Given the substantial interest in developing strategies for cancer detection and given the limited performance of CA125, our validation of a polyamine signature for early-stage ovarian cancer that complements CA125 provides supportive evidence for the utility of aberrant polyamine metabolism for cancer detection. Our findings provide a basis for the inclusion of the 3-marker panel on validation studies that encompass other biomarker candidates [26-28].

Author Contributions: Conceptualization, J.F.F., E.I., and S.H.; methodology, J.F.F., E.I., J.B.D., E.M., R.W., J.P.L., and K.-A.D.; validation, J.F.F. and E.I.; formal analysis, J.F.F. and E.I.; investigation, J.F.F. and E.I.; resources, M.K., J.C., K.H.L., Z.L., and R.C.B.J.; data curation, J.F.F., J.B.D., E.M., and R.W.; writing — original draft preparation, J.F.F. and E.I.; writing—review and editing, J.F.F., E.I., M.K., J.V., J.B.D., E.M., R.W., J.P.L., K.-A.D., J.C., K.H.L., Z.L., R.C.B.J., and S.H.; visualization, J.F.F. and E.I.; supervision, S.H.; project administration, J.B.D., R.C.B.J. and S.H.; funding acquisition, J.F.F., K.-A.D., and R.C.B.J. All authors have read and agreed to the published version of the manuscript.

Funding: Supported in part through the Cancer Prevention and Research Institute of Texas grants RP160145 and RP101382, the generous philanthropic contributions to The University of Texas MD Anderson Cancer Center Moon Shots Program ${ }^{\mathrm{TM}}$ and a faculty fellowship from The University of Texas MD Anderson Cancer Center Duncan Family Institute for Cancer Prevention and Risk Assessment (JFF). This work was also supported by grants from the NCI Early Detection Research Network (5 U01 CA200462-02), the MD Anderson Ovarian SPORE (P50 CA217685), National Cancer Institute, Department of Health and Human Services; Golfer's Against Cancer, the Mossy Foundation, the Roberson Endowment, and generous donations from Stuart and Gaye Lynn Zarrow. KAD was partially supported by National Institute of Health SPORE grant P50CA140388, CCTS grant 5UL1TR0003167, CPRIT grant RP160693 (KAD), and the National Cancer Institute grant CA016672. 
Institutional Review Board Statement: Ethical approval was obtained for these samples from the appropriate institutional review boards/ethic committees at MD Anderson and collaborating institutions under IRB protocol LAB04-0687.

Informed Consent Statement: Not applicable.

Data Availability Statement: Relevant data supporting the findings of this study are available within the Article and Appendix A or are available from the authors upon reasonable request.

Conflicts of Interest: Authors declare no conflicts of interest.

\section{Appendix A}

Appendix A.1. Metabolomics Analysis

Plasma metabolites were extracted from pre-aliquoted EDTA plasma $(10 \mu \mathrm{L})$ with 30 $\mu \mathrm{L}$ of LCMS grade methanol (ThermoFisher) in a 96-well microplate (Eppendorf). Plates were heat-sealed, vortexed for $5 \mathrm{~min}$ at $750 \mathrm{rpm}$, and centrifuged at $2000 \times g$ for $10 \mathrm{~min}$ at room temperature. The supernatant $(10 \mu \mathrm{L})$ was carefully transferred to a 96 -well plate, leaving behind the precipitated protein. The supernatant was further diluted with $10 \mu \mathrm{L}$ of $100 \mathrm{mM}$ ammonium formate, $\mathrm{pH}$. For hydrophilic interaction liquid chromatography (HILIC) analysis, the samples were diluted with $60 \mu \mathrm{L}$ LCMS grade acetonitrile (ThermoFisher), whereas samples for C18 analysis were diluted with $60 \mu \mathrm{L}$ water (GenPure ultrapure water system, Thermofisher). Each sample solution was transferred to 384-well microplate (Eppendorf) for LCMS analysis.

A total of 144 samples, plus quality control samples, were analyzed per batch per established operating procedures. Each batch was randomized, and the operator blinded; the ratio of cases to controls was equilibrated across each batch to mitigate bias. Matrixmatched reference-quality controls and batch-specific pooled quality controls were included in each batch.

\section{Appendix A.2. Analysis of Polyamines}

Semi-quantitative measurement of plasma polyamines was conducted on Waters Acquity $^{\mathrm{TM}}$ UPLC system with 2D column regeneration configuration (I-class and H-class) coupled to a Xevo G2-XS quadrupole time-of-flight (qTOF) mass spectrometer. Chromatographic separation was performed using HILIC (Acquity ${ }^{\mathrm{TM}}$ UPLC BEH amide, $100 \AA$, $1.7 \mu \mathrm{m} 2.1 \times 100 \mathrm{~mm}$, Waters Corporation, Milford, CT, USA) and C18 (Acquity ${ }^{\mathrm{TM}}$ UPLC HSS T3, $100 \AA$, $1.8 \mu \mathrm{m}, 2.1 \times 100 \mathrm{~mm}$, Water Corporation, Milford, U.S.A) columns at $45^{\circ} \mathrm{C}$.

Quaternary solvent system mobile phases were (A) $0.1 \%$ formic acid in water, (B) $0.1 \%$ formic acid in acetonitrile and (D) $100 \mathrm{mM}$ ammonium formate, $\mathrm{pH}$ 3. Samples were separated using the following gradient profile: for the HILIC separation, a starting gradient of $95 \% \mathrm{~B}$ and $5 \% \mathrm{D}$ was increased linearly to $70 \% \mathrm{~A}, 25 \% \mathrm{~B}$, and $5 \%$ D over a 5 min period at $0.4 \mathrm{~mL} / \mathrm{min}$ flow rate, followed by $1 \mathrm{~min}$ isocratic gradient at $100 \% \mathrm{~A}$ at $0.4 \mathrm{~mL} / \mathrm{min}$ flow rate. For C18 separation, a chromatography gradient of was as follows: starting conditions, $100 \% \mathrm{~A}$, with a linear increase to final conditions of $5 \% \mathrm{~A}, 95 \% \mathrm{~B}$ followed by isocratic gradient at $95 \% \mathrm{~B}, 5 \% \mathrm{D}$ for $1 \mathrm{~min}$.

A binary pump was used for column regeneration and equilibration. The solvent system mobile phases were (A1) $100 \mathrm{mM}$ ammonium formate, $\mathrm{pH} 3$, (A2) $0.1 \%$ formic in 2-propanol and (B1) $0.1 \%$ formic acid in acetonitrile. The HILIC column was stripped using $90 \%$ A2 for 5 min followed by 2 min equilibration using 100\% B1 at $0.3 \mathrm{~mL} / \mathrm{min}$ flowrate. Reverse phase C18 column regeneration was performed using 95\% A1, 5\% B1 for 2 min followed by column equilibration using 5\% A1, 95\% B1 for $5 \mathrm{~min}$.

\section{Appendix A.3. Mass Spectrometry Data Acquisition}

Mass spectrometry data were acquired in sensitivity and positive electrospray ionization mode within 50-1200 Da range. For the electrospray acquisition, the capillary voltage was set at $1.5 \mathrm{kV}$ (positive), sample cone voltage $30 \mathrm{~V}$, source temperature at $120^{\circ} \mathrm{C}$, cone 
gas flow $50 \mathrm{~L} / \mathrm{h}$ and desolvation gas flow rate of $800 \mathrm{~L} / \mathrm{h}$ with a scan time of $0.5 \mathrm{~s}$ in continuum mode. Leucine Enkephalin: $556.2771 \mathrm{Da}$ (positive) was used for lockspray correction and scans were performed at $0.5 \mathrm{~min}$. The injection volume for each sample was $6 \mu \mathrm{L}$, unless otherwise specified. The acquisition was carried out with instrument auto gain control to optimize instrument sensitivity over the samples acquisition time.

Pooled quality control samples were analyzed after a defined number of samples to assess replicate precision and allow LOESS correction by injection order. Additional data was captured using the MSe function for pooled quality control samples.

\section{Appendix A.4. Data Processing}

Peak picking and retention time alignment of LC-MS and MSe data were performed using Progenesis QI software (Nonlinear, Waters). Data processing and peak annotations were performed using an in-house automated pipeline. Annotations for polyamines were determined by matching accurate mass and retention times using customized libraries created from authentic standards and by matching experimental tandem mass spectrometry data against the NIST MSMS, LipidBlast or HMDB v3 theoretical fragmentations. To correct for injection order drift, each feature was normalized using data from repeat injections of quality control samples collected every 10 injections throughout the run sequence. Measurement data were smoothed by locally weighted scatterplot smoothing (LOESS) signal correction (QC-RLSC) as previously described [10,11]. Values were reported as ratios relative to the median of historical quality control reference samples run with every analytical batch for the given analyte.

Table A1. Detailed information on cases and control subjects presenting with benign pelvic masses.

\begin{tabular}{|c|c|c|c|c|}
\hline Condition & Description & Stage & GRADE & Set \\
\hline Case & Mixed Broderline and Endometrioid Adenocarcinoma & $2 \mathrm{~A}$ & II & Test Set \\
\hline Case & Serous carcinoma & $2 \mathrm{~A}$ & high & Test Set \\
\hline Case & Clear Cell Carcinoma & 2B & high & Test Set \\
\hline Case & Serous Carcinoma & 2B & high & Test Set \\
\hline Case & Serous carcinoma & $2 \mathrm{~B}$ & low & Test Set \\
\hline Case & Serous Carcinoma & $2 \mathrm{~B}$ & high & Test Set \\
\hline Case & Clear Cell Carcinoma & $2 \mathrm{C} 2$ & high & Test Set \\
\hline Case & Serous Carcinoma & $4 \mathrm{~B}$ & low & Test Set \\
\hline Case & Clear cell carcinoma & $\mathrm{I}$ & high & Test Set \\
\hline Case & clear cell carcinoma (CCC) & IA & high & Test Set \\
\hline Case & Endometrioid adenocarcinoma & IA & II & Test Set \\
\hline Case & Endometrioid adenocarcinoma & IA & I & Test Set \\
\hline Case & Endometrioid Adenocarcinoma & IA & II & Test Set \\
\hline Case & Endometrioid Adenocarcinoma & IA & II & Test Set \\
\hline Case & Endometrioid adenocarcinoma & IA & II & Test Set \\
\hline Case & Endometrioid adenocarcinoma & IA & I & Test Set \\
\hline Case & Mixed: endometrioid carcinoma, serous carcinoma & IA & low & Test Set \\
\hline Case & Mucinous Adenocarcinoma & IA & $\mathrm{n} / \mathrm{a}$ & Test Set \\
\hline Case & Mucinous carcinoma & IA & I & Test Set \\
\hline Case & Mucinous Carcinoma & IA & high & Test Set \\
\hline Case & Transitional cell carcinoma & IA & high & Test Set \\
\hline Case & Serous carcinoma & IA & low & Test Set \\
\hline
\end{tabular}


Table A1. Cont.

\begin{tabular}{|c|c|c|c|c|}
\hline Condition & Description & Stage & GRADE & Set \\
\hline Case & serous carcinoma & IA & high & Test Set \\
\hline Case & endometrioid adenocarcinoma & IB & II & Test Set \\
\hline Case & serous carcinoma & IB & high & Test Set \\
\hline Case & Serous Carcinoma & IB & high & Test Set \\
\hline Case & $\begin{array}{l}\text { Serous Carcinoma in background of mixed epithelial } \\
\text { borderline tumor }\end{array}$ & IB & low & Test Set \\
\hline Case & Clear cell carcinoma & IC & high & Test Set \\
\hline Case & Clear Cell Carcinoma & IC & high & Test Set \\
\hline Case & clear cell carcinoma (CCC) & IC & $\mathrm{n} / \mathrm{a}$ & Test Set \\
\hline Case & Endometrioid Adenocarcinoma & IC & II & Test Set \\
\hline Case & Endometrioid adenocarcinoma & IC & II & Test Set \\
\hline Case & Serous carcinoma & IC & high & Test Set \\
\hline Case & Serous carcinoma & IC & high & Test Set \\
\hline Case & Serous Carcinoma & IC & high & Test Set \\
\hline Case & Clear Cell Carcinoma & IC1 & high & Test Set \\
\hline Case & Carcinoma & IC1 & $\mathrm{n} / \mathrm{a}$ & Test Set \\
\hline Case & Serous Carcinoma & IC2 & high & Test Set \\
\hline Case & Mixed: Serous Carcinoma \& CCC & IC3 & high & Test Set \\
\hline Case & mucinous adenocarcinoma & II & $\mathrm{n} / \mathrm{a}$ & Test Set \\
\hline Case & mixed: undifferentiated carcinoma, serous carcinoma & IIA & high & Test Set \\
\hline Case & mixed: endometrioid carcinoma, serous carcinoma & IIB & high & Test Set \\
\hline Case & high serous carcinoma_III & III & high & Test Set \\
\hline Case & high serous carcinoma_III & III & high & Test Set \\
\hline Case & high serous carcinoma_III & III & high & Test Set \\
\hline Case & high serous carcinoma_III & III & high & Test Set \\
\hline Case & high serous carcinoma_III & III & high & Test Set \\
\hline Case & high serous carcinoma_III & III & high & Test Set \\
\hline Case & high serous carcinoma_III & III & high & Test Set \\
\hline Case & high serous carcinoma_III & III & high & Test Set \\
\hline Case & high serous carcinoma_III & III & high & Test Set \\
\hline Case & Serous Carcinoma & IIIA & high & Test Set \\
\hline Case & Serous carcinoma with minor endometrioid component & IIIA & high & Test Set \\
\hline Case & high Serous Carcinoma_IIIB & IIIB & high & Test Set \\
\hline Case & high Serous Carcinoma_"Advanced" & IIIC & high & Test Set \\
\hline Case & high serous carcinoma_IIIC & IIIC & high & Test Set \\
\hline Case & high serous carcinoma_IIIC & IIIC & high & Test Set \\
\hline Case & high serous carcinoma_IIIC & IIIC & high & Test Set \\
\hline Case & high serous carcinoma_IIIC & IIIC & high & Test Set \\
\hline Case & high serous carcinoma_IIIC & IIIC & high & Test Set \\
\hline Case & high Serous Carcinoma_IIIC & IIIC & high & Test Set \\
\hline
\end{tabular}


Table A1. Cont.

\begin{tabular}{|c|c|c|c|c|}
\hline Condition & Description & Stage & GRADE & Set \\
\hline Case & high Serous Carcinoma_IIIC & IIIC & high & Test Set \\
\hline Case & high Serous Carcinoma_IIIC & IIIC & high & Test Set \\
\hline Case & high Serous Carcinoma_IIIC & IIIC & high & Test Set \\
\hline Case & high Serous Carcinoma_IIIC & IIIC & high & Test Set \\
\hline Case & high serous carcinoma_IIII & IIIC & high & Test Set \\
\hline Case & high serous carcinoma_IIII & IIIC & high & Test Set \\
\hline Case & high serous carcinoma_IIII & IIIC & high & Test Set \\
\hline Case & high serous carcinoma_IIII & IIIC & high & Test Set \\
\hline Case & high serous carcinoma_IIII & IIIC & high & Test Set \\
\hline Case & high serous carcinoma_IIII & IIIC & high & Test Set \\
\hline Case & high serous carcinoma_IIII & IIIC & high & Test Set \\
\hline Case & high serous carcinoma_IIII & IIIC & high & Test Set \\
\hline Case & high serous carcinoma_IIII & IIIC & high & Test Set \\
\hline Case & high serous carcinoma_IIII & IIIC & high & Test Set \\
\hline Case & high serous carcinoma_IIII & IIIC & high & Test Set \\
\hline Case & high serous carcinoma_IIII & IIIC & high & Test Set \\
\hline Case & high serous carcinoma_IIII & IIIC & high & Test Set \\
\hline Case & high serous carcinoma_IIII & IIIC & high & Test Set \\
\hline Case & high serous carcinoma_IIII & IIIC & high & Test Set \\
\hline Case & high serous carcinoma_IIII & IIIC & high & Test Set \\
\hline Case & high serous carcinoma_IIII & IIIC & high & Test Set \\
\hline Case & high serous carcinoma_IIII & IIIC & high & Test Set \\
\hline Case & high serous carcinoma_IIII & IIIC & high & Test Set \\
\hline Case & high serous carcinoma_IIII & IIIC & high & Test Set \\
\hline Case & high serous carcinoma_IIII & IIIC & high & Test Set \\
\hline Case & high serous carcinoma_IIII & IIIC & high & Test Set \\
\hline Case & high serous carcinoma_IIII & IIIC & high & Test Set \\
\hline Case & high serous carcinoma_IIII & IIIC & high & Test Set \\
\hline Case & high serous carcinoma_IIII & IIIC & high & Test Set \\
\hline Case & high serous carcinoma_IIII & IIIC & high & Test Set \\
\hline Case & high serous carcinoma_IIII & IIIC & high & Test Set \\
\hline Case & high serous carcinoma_IIII & IIIC & high & Test Set \\
\hline Case & high serous carcinoma_IIII & IIIC & high & Test Set \\
\hline Case & high serous carcinoma_IIII & IIIC & high & Test Set \\
\hline Case & high serous carcinoma_IIII & IIIC & high & Test Set \\
\hline Case & high serous carcinoma_IIII & IIIC & high & Test Set \\
\hline Case & high serous carcinoma_IIII & IIIC & high & Test Set \\
\hline Case & high serous carcinoma_IIII & IIIC & high & Test Set \\
\hline Case & high serous carcinoma_IIII & IIIC & high & Test Set \\
\hline Case & high serous carcinoma_IIII & IIIC & high & Test Set \\
\hline
\end{tabular}


Table A1. Cont.

\begin{tabular}{|c|c|c|c|c|}
\hline Condition & Description & Stage & GRADE & Set \\
\hline Case & high serous carcinoma_IIII & IIIC & high & Test Set \\
\hline Case & high serous carcinoma_IIII & IIIC & high & Test Set \\
\hline Case & high serous carcinoma_IIII & IIIC & high & Test Set \\
\hline Case & high serous carcinoma_IIII & IIIC & high & Test Set \\
\hline Case & high serous carcinoma_IIII & IIIC & high & Test Set \\
\hline Case & high serous carcinoma_IV & IV & high & Test Set \\
\hline Case & high serous carcinoma_IV & IV & high & Test Set \\
\hline Case & high serous carcinoma_IV & IV & high & Test Set \\
\hline Case & high serous carcinoma_IV & IV & high & Test Set \\
\hline Case & high serous carcinoma_IV & IV & high & Test Set \\
\hline Case & high serous carcinoma_IV & IV & high & Test Set \\
\hline Case & high serous carcinoma_IV & IV & high & Test Set \\
\hline Case & high serous carcinoma_IV & IV & high & Test Set \\
\hline Case & high serous carcinoma_IV & IV & high & Test Set \\
\hline Case & high Serous Carcinoma_IV & IV & high & Test Set \\
\hline Case & serous carcinoma & I & high & Validation Set \\
\hline Case & endometrioid adenocarcinoma & I & I & Validation Set \\
\hline Case & mixed: endometrioid carcinoma, serous borderline tumor & I & II & Validation Set \\
\hline Case & Serous Carcinoma & I & high & Validation Set \\
\hline Case & serous carcinoma & I & high & Validation Set \\
\hline Case & endometrioid adenocarcinoma & I & I & Validation Set \\
\hline Case & Endometrioid Adenocarcinoma & IA & II & Validation Set \\
\hline Case & serous carcinoma & IA & high & Validation Set \\
\hline Case & $\begin{array}{l}\text { mixed: endometrioid adenocarcinoma, clear cell carcinoma } \\
\qquad(C C C)\end{array}$ & IA & high & Validation Set \\
\hline Case & endometrioid adenocarcinoma & IA & $\mathrm{I}$ & Validation Set \\
\hline Case & mucinous adenocarcinoma & IA & $\mathrm{n} / \mathrm{a}$ & Validation Set \\
\hline Case & Serous Mucinous Carcinoma & IA & $\mathrm{n} / \mathrm{a}$ & Validation Set \\
\hline Case & Serous Carcinoma & IA & high & Validation Set \\
\hline Case & serous carcinoma & IA & high & Validation Set \\
\hline Case & mucinous adenocarcinoma & IA & II & Validation Set \\
\hline Case & $\begin{array}{l}\text { Endometrioid Adenocarcinoma, Mucinous Carcinoma, Clear } \\
\text { Cell Carcinoma }\end{array}$ & IA & $\begin{array}{l}\text { Mixed high } \\
\text { and low }\end{array}$ & Validation Set \\
\hline Case & mixed: papillary serous carcinoma, endometrioid carcinoma & IA & high & Validation Set \\
\hline Case & clear cell carcinoma (CCC) & IA & high & Validation Set \\
\hline Case & endometrioid adenocarcinoma & IA & high & Validation Set \\
\hline Case & serous adenocarcinoma & IA & high & Validation Set \\
\hline Case & serous carcinoma & IA & high & Validation Set \\
\hline Case & clear cell carcinoma (CCC) & IA & high & Validation Set \\
\hline Case & endometrioid adenocarcinoma & IB & II & Validation Set \\
\hline Case & carcinoma & IB & high & Validation Set \\
\hline
\end{tabular}


Table A1. Cont.

\begin{tabular}{|c|c|c|c|c|}
\hline Condition & Description & Stage & GRADE & Set \\
\hline Case & Mixed Serous and Endometrioid Carcinoma & IC & high & Validation Set \\
\hline Case & endometrioid adenocarcinoma & IC & II & Validation Set \\
\hline Case & endometrioid adenocarcinoma & IC & II & Validation Set \\
\hline Case & endometrioid adenocarcinoma & IC & III & Validation Set \\
\hline Case & Clear Cell Carcinoma & IC & high & Validation Set \\
\hline Case & endometrioid adenocarcinoma & IC & I & Validation Set \\
\hline Case & $\begin{array}{c}\text { mixed: endometrioid carcinoma, ovarian carcinoma, } \\
\text { peritoneal carcinoma }\end{array}$ & IC & II & Validation Set \\
\hline Case & mucinous carcinoma & IC & low & Validation Set \\
\hline Case & serous carcinoma & IC & low & Validation Set \\
\hline Case & serous carcinoma & IC & high & Validation Set \\
\hline Case & mixed: endometrioid carcinoma, clear cell carcinoma (CCC) & IC & high & Validation Set \\
\hline Case & mucinous adenocarcinoma & IC & I & Validation Set \\
\hline Case & mucinous carcinoma & IC & $\mathrm{n} / \mathrm{a}$ & Validation Set \\
\hline Case & Mucinous Carcinoma & IC & II & Validation Set \\
\hline Case & endometrioid adenocarcinoma & II & II & Validation Set \\
\hline Case & Endometroid Adenocarcinoma & II & $\mathrm{n} / \mathrm{a}$ & Validation Set \\
\hline Case & mixed: transitional carcinoma, squamous cell carcinoma & II & high & Validation Set \\
\hline Case & Serous Carcinoma & II & high & Validation Set \\
\hline Case & serous carcinoma & IIA & high & Validation Set \\
\hline Case & endometrioid adenocarcinoma & IIA & III & Validation Set \\
\hline Case & Serous Carcinoma & IIA & High & Validation Set \\
\hline Case & mixed: undifferentiated carcinoma, serous carcinoma & IIA & high & Validation Set \\
\hline Case & mixed: endometrioid carcinoma, serous carcinoma & IIB & high & Validation Set \\
\hline Case & Serous Carcinoma, Adenocarcinoma & IIB & High & Validation Set \\
\hline Case & endometrioid adenocarcinoma & IIB & II & Validation Set \\
\hline Case & serous carcinoma & IIB & low & Validation Set \\
\hline Case & mixed: serous carcinoma, endometrioid carcinoma & IIB & high & Validation Set \\
\hline Case & serous carcinoma & IIB & high & Validation Set \\
\hline Case & $\begin{array}{l}\text { mixed: mucinous endometrioid carcinoma, clear cell } \\
\text { carcinoma (CCC) }\end{array}$ & IIB & high & Validation Set \\
\hline Case & serous carcinoma & IIB & high & Validation Set \\
\hline Case & Serous Carcinoma & IIB & high & Validation Set \\
\hline Case & Serous Carcinoma & IIB & high & Validation Set \\
\hline Case & serous carcinoma & IIB & high & Validation Set \\
\hline Case & serous carcinoma & IIC & high & Validation Set \\
\hline Case & Serous Carcinoma & IIC & high & Validation Set \\
\hline Case & Clear Cell Carcinoma & IIC & $\mathrm{n} / \mathrm{a}$ & Validation Set \\
\hline Case & Serous Carcinoma & IIC & Low & Validation Set \\
\hline $\begin{array}{l}\text { Benign Pelvic } \\
\text { Mass }\end{array}$ & Serous adenofibroma & - & - & Test Set \\
\hline $\begin{array}{l}\text { Benign Pelvic } \\
\text { Mass }\end{array}$ & Serous Cystadoma & - & - & Test Set \\
\hline
\end{tabular}


Table A1. Cont.

\begin{tabular}{|c|c|c|c|c|}
\hline Condition & Description & Stage & GRADE & Set \\
\hline $\begin{array}{c}\text { Benign Pelvic } \\
\text { Mass }\end{array}$ & Mucinous Cystadenoma & - & - & Test Set \\
\hline $\begin{array}{c}\text { Benign Pelvic } \\
\text { Mass }\end{array}$ & Mucinous Cystadenofribroma & - & - & Test Set \\
\hline $\begin{array}{c}\text { Benign Pelvic } \\
\text { Mass }\end{array}$ & Endometriotic Cyst & - & - & Test Set \\
\hline $\begin{array}{l}\text { Benign Pelvic } \\
\text { Mass }\end{array}$ & mucinous neoplasm & - & - & Test Set \\
\hline $\begin{array}{c}\text { Benign Pelvic } \\
\text { Mass }\end{array}$ & serous cystadenomas & - & - & Test Set \\
\hline $\begin{array}{l}\text { Benign Pelvic } \\
\text { Mass }\end{array}$ & Fibroma & - & - & Test Set \\
\hline $\begin{array}{c}\text { Benign Pelvic } \\
\text { Mass }\end{array}$ & serous cystadenofibroma & - & - & Test Set \\
\hline $\begin{array}{l}\text { Benign Pelvic } \\
\text { Mass }\end{array}$ & serous cystadenoma & - & - & Test Set \\
\hline $\begin{array}{l}\text { Benign Pelvic } \\
\text { Mass }\end{array}$ & Mucinous Cystadenoma & - & - & Test Set \\
\hline $\begin{array}{c}\text { Benign Pelvic } \\
\text { Mass }\end{array}$ & Fibroma & - & - & Test Set \\
\hline $\begin{array}{l}\text { Benign Pelvic } \\
\text { Mass }\end{array}$ & Serous cystadenoma & - & - & Test Set \\
\hline $\begin{array}{l}\text { Benign Pelvic } \\
\text { Mass }\end{array}$ & Cyst \& Rete Cystadonoma & - & - & Test Set \\
\hline $\begin{array}{l}\text { Benign Pelvic } \\
\text { Mass }\end{array}$ & $\begin{array}{l}\text { Peritoneal Inclusion Cysts, Follicular Cysts, Corpus Luteal } \\
\text { Cysts }\end{array}$ & - & - & Test Set \\
\hline $\begin{array}{c}\text { Benign Pelvic } \\
\text { Mass }\end{array}$ & serous cystadenofibroma & - & - & Test Set \\
\hline $\begin{array}{l}\text { Benign Pelvic } \\
\text { Mass }\end{array}$ & endometrioma, endometriosis & - & - & Test Set \\
\hline $\begin{array}{c}\text { Benign Pelvic } \\
\text { Mass }\end{array}$ & cystadenoma and severe pelvic adhesive disease & - & - & Test Set \\
\hline $\begin{array}{c}\text { Benign Pelvic } \\
\text { Mass }\end{array}$ & cystadenofibroma & - & - & Test Set \\
\hline $\begin{array}{l}\text { Benign Pelvic } \\
\text { Mass }\end{array}$ & Endometriotic cyst & - & - & Test Set \\
\hline $\begin{array}{l}\text { Benign Pelvic } \\
\text { Mass }\end{array}$ & cyst & - & - & Test Set \\
\hline $\begin{array}{l}\text { Benign Pelvic } \\
\text { Mass }\end{array}$ & ovarian mass & - & - & Test Set \\
\hline $\begin{array}{l}\text { Benign Pelvic } \\
\text { Mass }\end{array}$ & Mucinous Cystadenoma & - & - & Test Set \\
\hline $\begin{array}{l}\text { Benign Pelvic } \\
\text { Mass }\end{array}$ & mucinous cystadenoma & - & - & Test Set \\
\hline $\begin{array}{l}\text { Benign Pelvic } \\
\text { Mass }\end{array}$ & fibroma, cysts & - & - & Test Set \\
\hline $\begin{array}{c}\text { Benign Pelvic } \\
\text { Mass }\end{array}$ & mucinous cystadenoma & - & - & Test Set \\
\hline
\end{tabular}


Table A1. Cont.

\begin{tabular}{|c|c|c|c|c|}
\hline Condition & Description & Stage & GRADE & Set \\
\hline $\begin{array}{l}\text { Benign Pelvic } \\
\text { Mass }\end{array}$ & mucinous cystadenoma, intestinal & - & - & Test Set \\
\hline $\begin{array}{c}\text { Benign Pelvic } \\
\text { Mass }\end{array}$ & Mucinous cystadenoma & - & - & Test Set \\
\hline $\begin{array}{c}\text { Benign Pelvic } \\
\text { Mass }\end{array}$ & bilateral endometriomas & - & - & Test Set \\
\hline $\begin{array}{c}\text { Benign Pelvic } \\
\text { Mass }\end{array}$ & Mucinous Cystadenoma & - & - & Test Set \\
\hline $\begin{array}{c}\text { Benign Pelvic } \\
\text { Mass }\end{array}$ & Endometriotic Cyst & - & - & Test Set \\
\hline $\begin{array}{c}\text { Benign Pelvic } \\
\text { Mass }\end{array}$ & cyst & - & - & Test Set \\
\hline $\begin{array}{c}\text { Benign Pelvic } \\
\text { Mass }\end{array}$ & cystadenoma & - & - & Test Set \\
\hline $\begin{array}{c}\text { Benign Pelvic } \\
\text { Mass }\end{array}$ & Mucinous cystadenoma & - & - & Test Set \\
\hline $\begin{array}{c}\text { Benign Pelvic } \\
\text { Mass }\end{array}$ & cyst & - & - & Test Set \\
\hline $\begin{array}{c}\text { Benign Pelvic } \\
\text { Mass }\end{array}$ & Endometriotic cyst & - & - & Test Set \\
\hline $\begin{array}{c}\text { Benign Pelvic } \\
\text { Mass }\end{array}$ & Cysts & - & - & Test Set \\
\hline $\begin{array}{c}\text { Benign Pelvic } \\
\text { Mass }\end{array}$ & serous ovarian cystadenofibroma of LOV & - & - & Test Set \\
\hline $\begin{array}{c}\text { Benign Pelvic } \\
\text { Mass }\end{array}$ & benign mass & - & - & Test Set \\
\hline $\begin{array}{c}\text { Benign Pelvic } \\
\text { Mass }\end{array}$ & Luteal Cyst & - & - & Test Set \\
\hline $\begin{array}{c}\text { Benign Pelvic } \\
\text { Mass }\end{array}$ & mucinous cystadenoma & - & - & Test Set \\
\hline $\begin{array}{c}\text { Benign Pelvic } \\
\text { Mass }\end{array}$ & serous cystadenoma & - & - & Test Set \\
\hline $\begin{array}{c}\text { Benign Pelvic } \\
\text { Mass }\end{array}$ & Serous Cystadenofibroma & - & - & Test Set \\
\hline $\begin{array}{c}\text { Benign Pelvic } \\
\text { Mass }\end{array}$ & Serous Cystadenofibroma & - & - & Test Set \\
\hline $\begin{array}{c}\text { Benign Pelvic } \\
\text { Mass }\end{array}$ & serous cyst & - & - & Test Set \\
\hline $\begin{array}{c}\text { Benign Pelvic } \\
\text { Mass }\end{array}$ & cystadenoma & - & - & Test Set \\
\hline $\begin{array}{c}\text { Benign Pelvic } \\
\text { Mass }\end{array}$ & Mucinous Cystadenofribroma & - & - & Test Set \\
\hline $\begin{array}{c}\text { Benign Pelvic } \\
\text { Mass }\end{array}$ & mucinous cystadenoma & - & - & Test Set \\
\hline $\begin{array}{c}\text { Benign Pelvic } \\
\text { Mass }\end{array}$ & serous cystadenoma & - & - & Test Set \\
\hline $\begin{array}{c}\text { Benign Pelvic } \\
\text { Mass }\end{array}$ & Cysts & - & - & Test Set \\
\hline
\end{tabular}


Table A1. Cont.

\begin{tabular}{|c|c|c|c|c|}
\hline Condition & Description & Stage & GRADE & Set \\
\hline $\begin{array}{c}\text { Benign Pelvic } \\
\text { Mass }\end{array}$ & mucinous cystadenoma & - & - & Test Set \\
\hline $\begin{array}{c}\text { Benign Pelvic } \\
\text { Mass }\end{array}$ & endometrioma & - & - & Test Set \\
\hline $\begin{array}{c}\text { Benign Pelvic } \\
\text { Mass }\end{array}$ & Fibroma & - & - & Test Set \\
\hline $\begin{array}{l}\text { Benign Pelvic } \\
\text { Mass }\end{array}$ & Sertoli-Leydig cell & - & - & Test Set \\
\hline $\begin{array}{c}\text { Benign Pelvic } \\
\text { Mass }\end{array}$ & serous cystadenofibroma & - & - & Test Set \\
\hline $\begin{array}{c}\text { Benign Pelvic } \\
\text { Mass }\end{array}$ & endometrioisis, atypia & - & - & Test Set \\
\hline $\begin{array}{c}\text { Benign Pelvic } \\
\text { Mass }\end{array}$ & mucinous cystadenoma & - & - & Test Set \\
\hline $\begin{array}{c}\text { Benign Pelvic } \\
\text { Mass }\end{array}$ & Benign Luteal Cyst & - & - & Test Set \\
\hline $\begin{array}{c}\text { Benign Pelvic } \\
\text { Mass }\end{array}$ & Endometriosis & - & - & Test Set \\
\hline $\begin{array}{c}\text { Benign Pelvic } \\
\text { Mass }\end{array}$ & Cystadenofibroma & - & - & Test Set \\
\hline $\begin{array}{l}\text { Benign Pelvic } \\
\text { Mass }\end{array}$ & Cyst & - & - & Test Set \\
\hline $\begin{array}{c}\text { Benign Pelvic } \\
\text { Mass }\end{array}$ & cysts & - & - & Test Set \\
\hline $\begin{array}{c}\text { Benign Pelvic } \\
\text { Mass }\end{array}$ & (LOV) fibroma & - & - & Test Set \\
\hline $\begin{array}{c}\text { Benign Pelvic } \\
\text { Mass }\end{array}$ & endometrioic cysts & - & - & Test Set \\
\hline $\begin{array}{c}\text { Benign Pelvic } \\
\text { Mass }\end{array}$ & serous cystadenofibroma & - & - & Test Set \\
\hline $\begin{array}{c}\text { Benign Pelvic } \\
\text { Mass }\end{array}$ & Serous Cystadenofibroma & - & - & Test Set \\
\hline $\begin{array}{c}\text { Benign Pelvic } \\
\text { Mass }\end{array}$ & Mucinous Cystadenona & - & - & Test Set \\
\hline $\begin{array}{c}\text { Benign Pelvic } \\
\text { Mass }\end{array}$ & Mucinous Cystadenoma & - & - & Test Set \\
\hline $\begin{array}{c}\text { Benign Pelvic } \\
\text { Mass }\end{array}$ & corpus albicanocyst, fibrosis & - & - & Test Set \\
\hline $\begin{array}{c}\text { Benign Pelvic } \\
\text { Mass }\end{array}$ & fibroma & - & - & Test Set \\
\hline $\begin{array}{c}\text { Benign Pelvic } \\
\text { Mass }\end{array}$ & brenner tumor & - & - & Test Set \\
\hline $\begin{array}{c}\text { Benign Pelvic } \\
\text { Mass }\end{array}$ & fibrothecoma of ROV & - & - & Test Set \\
\hline
\end{tabular}


Table A2. Polyamines detected and measured by liquid chromatography mass spectrometry.

\begin{tabular}{ccccc}
\hline Metabolite & Adduct & $\mathbf{m} / \mathbf{z}$ & $\begin{array}{c}\text { Retention Time } \\
\text { (min) }\end{array}$ & Assay + \\
\hline Acetylspermidine & {$[\mathrm{M}+\mathrm{H}]+$} & 188.1751 & 3.85 & P_HA \\
\hline Diacetylspermidine & {$[\mathrm{M}+\mathrm{H}]+$} & 230.1858 & 3.11 & P_HA \\
\hline Diacetylspermine & {$[\mathrm{M}+\mathrm{H}]+$} & 287.2418 & 3.72 & P_HA \\
\hline N-(3-acetamidopropyl)pyrrolidin-2-one & {$[\mathrm{M}+\mathrm{H}]+$} & 185.1277 & 2.12 & P_CA \\
\hline
\end{tabular}

$\uparrow \mathrm{P}$ : electrospray ionization positive mode acquisition; HA- HILIC acidic; CA- C18 acidic.

Table A3. Coefficient of variation (CV) values for measured polyamines in pooled quality control samples.

\begin{tabular}{cccccccc}
\hline $\begin{array}{c}\text { Coefficient of Variation Values } \\
\text { for Measured Polyamines }\end{array}$ & \multicolumn{5}{c}{ Coefficient of Variation (CV) Values } \\
\hline & \multicolumn{3}{c}{ Test Set } \\
\hline Batch 1 & \multicolumn{2}{c}{ Batch 2 } & \multicolumn{2}{c}{ Balidation Set } \\
\hline DAS & HQC & PQC & HQC & PQC & HQC & PQC \\
\hline AcSpmd & 21.26 & 4.52 & 5.57 & 3.25 & 11.68 & 5.29 \\
\hline DiAcspmd & 4.61 & 3.25 & 5.19 & 2.02 & 21.29 & 2.58 \\
\hline N3AP & 6.56 & 6.66 & 5.61 & 4.08 & 15.21 & 4.86 \\
\hline & 5.61 & 2.96 & 3.64 & 4.74 & 3.5 & 1.85
\end{tabular}

Abbreviation: DAS- diacetylspermine; AcSpmd- Acetylspermidine; DiAcspmd- Diacetylspermidine; N3AP$\mathrm{N}$-(3-acetamidopropyl)pyrrolidin-2-one.

Table A4. Classification performances of plasma polyamines in distinguishing ovarian cancer cases from controls in the Test Set.

\begin{tabular}{|c|c|c|c|c|c|c|c|c|c|c|c|c|c|c|c|}
\hline \multirow[b]{2}{*}{ Metabolite } & \multicolumn{5}{|c|}{$\begin{array}{l}\text { All OvCa Cases }(n=116) \text { vs. } \\
\text { Healthy Controls }(n=71)\end{array}$} & \multicolumn{5}{|c|}{$\begin{array}{c}\text { Early Stage OvCa Cases }(n=41) \text { vs. } \\
\text { Healthy Controls }(n=71)\end{array}$} & \multicolumn{5}{|c|}{$\begin{array}{c}\text { Late Stage OvCa Cases }(n=75) \text { vs. } \\
\text { Healthy Controls }(n=71)\end{array}$} \\
\hline & AUC & $\begin{array}{l}95 \% \\
\mathrm{CI}\end{array}$ & $p+$ & $\begin{array}{l}\text { Sens @ } \\
95 \% \text { Spec }\end{array}$ & $\begin{array}{l}\text { Spec @ } \\
95 \% \text { Sens }\end{array}$ & AUC & $\begin{array}{l}95 \% \\
\mathrm{CI}\end{array}$ & $p+$ & $\begin{array}{l}\text { Sens @ } \\
95 \% \text { Spec }\end{array}$ & $\begin{array}{l}\text { Spec@ } \\
95 \% \text { Sens }\end{array}$ & AUC & $\begin{array}{l}95 \% \\
\mathrm{CI}\end{array}$ & $p+$ & $\begin{array}{l}\text { Sens @ } \\
95 \% \text { Spec }\end{array}$ & $\begin{array}{l}\text { Spec@ } \\
95 \% \text { Sens }\end{array}$ \\
\hline Diacetylspermine & 0.88 & $\begin{array}{l}0.84- \\
0.93\end{array}$ & $<0.001$ & 47.4 & 59.2 & 0.82 & $\begin{array}{l}0.74- \\
0.90\end{array}$ & $<0.001$ & 43.9 & 43.7 & 0.92 & $\begin{array}{l}0.88- \\
0.96\end{array}$ & $<0.001$ & 49.3 & 73.2 \\
\hline Diacetylspermidine & 0.74 & $\begin{array}{l}0.66- \\
0.82\end{array}$ & $<0.001$ & 8.6 & 35.2 & 0.76 & $\begin{array}{l}0.67- \\
0.85\end{array}$ & $<0.001$ & 22.0 & 31.0 & 0.73 & $\begin{array}{l}0.64- \\
0.82\end{array}$ & $<0.001$ & 1.3 & 50.7 \\
\hline Acetylspermidine & 0.76 & $\begin{array}{l}0.69- \\
0.83\end{array}$ & $<0.001$ & 29.3 & 19.7 & 0.70 & $\begin{array}{l}0.59- \\
0.81\end{array}$ & $<0.001$ & 29.3 & 5.6 & 0.79 & $\begin{array}{l}0.72- \\
0.87\end{array}$ & $<0.001$ & 29.3 & 38.0 \\
\hline \multirow[t]{2}{*}{ N3AP } & 0.75 & $\begin{array}{l}0.67- \\
0.82\end{array}$ & $<0.001$ & 18.1 & 21.1 & 0.72 & $\begin{array}{l}0.62- \\
0.82\end{array}$ & $<0.001$ & 19.5 & 21.1 & 0.76 & $\begin{array}{l}0.69- \\
0.84\end{array}$ & $<0.001$ & 17.3 & 32.4 \\
\hline & \multicolumn{5}{|c|}{$\begin{array}{c}\text { All OvCa Cases }(n=116) \text { vs. } \\
\text { Subjects with Benign Cysts }(n=72)\end{array}$} & \multicolumn{5}{|c|}{$\begin{array}{l}\text { Early Stage OvCa Cases }(n=41) \text { vs. } \\
\text { Subjects with Benign Cysts }(n=72)\end{array}$} & \multicolumn{5}{|c|}{$\begin{array}{l}\text { Late Stage OvCa Cases }(n=75) \text { vs. } \\
\text { Subjects with Benign Cysts }(n=72)\end{array}$} \\
\hline Metabolite & AUC & $\begin{array}{l}95 \% \\
\mathrm{CI}\end{array}$ & $p+$ & $\begin{array}{l}\text { Sens @ } \\
95 \% \text { Spec }\end{array}$ & $\begin{array}{l}\text { Spec @ } \\
95 \% \text { Sens }\end{array}$ & AUC & $\begin{array}{l}95 \% \\
\text { CI }\end{array}$ & $p+$ & $\begin{array}{l}\text { Sens @ } \\
95 \% \text { Spec }\end{array}$ & $\begin{array}{l}\text { Spec@ } \\
95 \% \text { Sens }\end{array}$ & AUC & $\begin{array}{l}95 \% \\
\mathrm{CI}\end{array}$ & $p+$ & $\begin{array}{l}\text { Sens @ } \\
95 \% \text { Spec }\end{array}$ & $\begin{array}{l}\text { Spec @ } \\
95 \% \text { Sens }\end{array}$ \\
\hline Diacetylspermine & 0.78 & $\begin{array}{l}0.72- \\
0.85\end{array}$ & $<0.001$ & 28.4 & 34.7 & 0.70 & $\begin{array}{l}0.60- \\
0.81\end{array}$ & $\begin{array}{c}< \\
0.001\end{array}$ & 24.4 & 22.2 & 0.83 & $\begin{array}{l}0.76- \\
0.89\end{array}$ & $<0.001$ & 30.7 & 56.9 \\
\hline Diacetylspermidine & 0.52 & $\begin{array}{l}0.43- \\
0.60\end{array}$ & 0.73 & 0 & 2.8 & 0.58 & $\begin{array}{l}0.46- \\
0.70\end{array}$ & 0.17 & 17.1 & 5.6 & 0.57 & $\begin{array}{l}0.47- \\
0.66\end{array}$ & 0.17 & 0 & 18.1 \\
\hline Acetylspermidine & 0.53 & $\begin{array}{l}0.45- \\
0.61\end{array}$ & 0.50 & 17.2 & 0 & 0.50 & $\begin{array}{l}0.38- \\
0.63\end{array}$ & 0.98 & 22.0 & 0 & 0.55 & $\begin{array}{l}0.45- \\
0.64\end{array}$ & 0.33 & 16.0 & 2.8 \\
\hline N3AP & 0.58 & $\begin{array}{l}0.50- \\
0.66\end{array}$ & 0.06 & 19.0 & 1.4 & 0.55 & $\begin{array}{l}0.43- \\
0.67\end{array}$ & 0.38 & 22.0 & 1.4 & 0.60 & $\begin{array}{l}0.51- \\
0.69\end{array}$ & 0.04 & 17.3 & 5.6 \\
\hline
\end{tabular}


Table A5. Classification performance of plasma polyamines in distinguishing serous and non-serous cases from controls in the Test Set.

\begin{tabular}{|c|c|c|c|c|c|c|c|c|c|c|}
\hline \multirow[b]{2}{*}{ Metabolite } & \multicolumn{5}{|c|}{ All Serous Cases $(n=91)$ vs. Healthy Controls $(n=71)$} & \multicolumn{5}{|c|}{ All Serous Cases $(n=91)$ vs. Subjects with Benign Cysts $(n=72)$} \\
\hline & AUC & $95 \% \mathrm{CI}$ & $p+$ & Sens @ 95\% Spec & Spec@ 95\% Sens & AUC & $95 \% \mathrm{CI}$ & $p+$ & Sens @ 95\% Spec & Spec@ 95\% Sens \\
\hline Diacetylspermine & 0.9 & $0.85-0.95$ & $<0.001$ & 47.3 & 69 & 0.8 & $0.74-0.87$ & $<0.001$ & 28.6 & 47.2 \\
\hline Diacetylspermidine & 0.73 & $0.64-0.81$ & $<0.001$ & 3.3 & 39.4 & 0.55 & $0.46-0.64$ & 0.28 & 0 & 9.7 \\
\hline Acetylspermidine & 0.77 & $0.69-0.84$ & $<0.001$ & 29.7 & 23.9 & 0.53 & $0.44-0.62$ & 0.5 & 16.5 & 0 \\
\hline N3AP & 0.75 & $0.68-0.83$ & $<0.001$ & 17.6 & 32.4 & 0.58 & $0.50-0.67$ & 0.07 & 17.6 & 5.6 \\
\hline & \multicolumn{5}{|c|}{ Early Stage Serous Cases $(n=16)$ vs. Healthy Controls $(n=71)$} & \multicolumn{5}{|c|}{$\begin{array}{l}\text { Early Stage Serous Cases }(n=16) \text { vs. Subjects with Benign Disease } \\
\qquad(n=72)\end{array}$} \\
\hline Metabolite & AUC & $95 \% \mathrm{CI}$ & $p+$ & Sens@ 95\% Spec & Spec@ 95\% Sens & AUC & $95 \% \mathrm{CI}$ & $p+$ & Sens @ 95\% Spec & Spec@ 95\% Sens \\
\hline Diacetylspermine & 0.81 & $0.69-0.94$ & $<0.001$ & 37.5 & 4.2 & 0.7 & $0.56-0.84$ & 0.01 & 18.8 & 5.6 \\
\hline Diacetylspermidine & 0.74 & $0.62-0.87$ & 0.003 & 12.5 & 25.4 & 0.47 & $0.30-0.64$ & 0.74 & 0 & 2.8 \\
\hline Acetylspermidine & 0.66 & $0.49-0.83$ & 0.049 & 31.3 & 4.2 & 0.54 & $0.34-0.75$ & 0.58 & 31.3 & 0 \\
\hline \multirow[t]{2}{*}{ N3AP } & 0.7 & $0.56-0.84$ & 0.01 & 18.8 & 18.3 & 0.51 & $0.34-0.68$ & 0.94 & 18.8 & 0 \\
\hline & \multicolumn{5}{|c|}{ Late Stage Serous Cases $(n=75)$ vs. Healthy Controls $(n=71)$} & \multicolumn{5}{|c|}{$\begin{array}{l}\text { Late Stage Serous Cases }(n=75) \text { vs. Subjects with Benign Disease } \\
\qquad(n=72)\end{array}$} \\
\hline Metabolite & AUC & $95 \%$ CI & $p+$ & Sens @ 95\% Spec & Spec@ 95\% Sens & AUC & $95 \% \mathrm{CI}$ & $p+$ & Sens@ 95\% Spec & Spec @ 95\% Sens \\
\hline Diacetylspermine & 0.92 & $0.88-0.96$ & $<0.001$ & 49.3 & 73.2 & 0.83 & $0.76-0.89$ & $<0.001$ & 30.7 & 56.9 \\
\hline Diacetylspermidine & 0.73 & $0.64-0.82$ & $<0.001$ & 1.3 & 50.7 & 0.57 & $0.47-0.66$ & 0.17 & 0 & 18.1 \\
\hline Acetylspermidine & 0.79 & $0.72-0.87$ & $<0.001$ & 29.3 & 38 & 0.55 & $0.45-0.64$ & 0.33 & 16 & 2.8 \\
\hline \multirow[t]{2}{*}{ N3AP } & 0.76 & $0.69-0.84$ & $<0.001$ & 17.3 & 32.4 & 0.6 & $0.51-0.69$ & 0.04 & 17.3 & 5.6 \\
\hline & \multicolumn{5}{|c|}{ Non-Serous Cases $(n=25)$ vs. Healthy Controls $(n=71)$} & \multicolumn{5}{|c|}{ Non-Serous Cases $(n=25)$ vs. Subjects with Benign Disease $(n=72)$} \\
\hline Metabolite & AUC & $95 \% \mathrm{CI}$ & $p+$ & Sens@ 95\% Spec & Spec@ 95\% Sens & AUC & $95 \% \mathrm{CI}$ & $p+$ & Sens@ 95\% Spec & Spec@ 95\% Sens \\
\hline Diacetylspermine & 0.83 & $0.73-0.92$ & $<0.001$ & 48 & 43.7 & 0.71 & $0.58-0.83$ & 0.002 & 28 & 22.2 \\
\hline Diacetylspermidine & 0.77 & $0.67-0.88$ & $<0.001$ & 28,0 & 31 & 0.61 & $0.46-0.76$ & 0.1 & 24 & 5.6 \\
\hline Acetylspermidine & 0.72 & $0.59-0.85$ & 0.001 & 28 & 5.6 & 0.53 & $0.37-0.68$ & 0.71 & 20 & 0 \\
\hline N3AP & 0.73 & $0.61-0.85$ & $<0.001$ & 20 & 21.1 & 0.58 & $0.43-0.73$ & 0.25 & 24 & 1.4 \\
\hline
\end{tabular}

† Significance was determined by 2-sided Wilcoxon rank sum test.

Table A6. Sensitivity of the 3-marker panel and CA125 alone at specificity cutoff values of 99\%, $98.5 \%$ and $97 \%$ in the Test Set and Validation Set.

\begin{tabular}{cccc}
\hline & \multicolumn{3}{c}{ Test Set } \\
\hline Cutoffs & DAS + N3AP + CA125 & CA125 & McNemar Exact Test 1-sided $p$-value \\
\hline Sensivitiy @ 99\% Specificity & 46.3 & 24.3 & 0.006 \\
Sensivitiy @ 98.5\% Specificity & 48.8 & 34.1 & 0.04 \\
Sensivitiy @ 97\% Specificity & 48.8 & 39.2 & 0.17 \\
\hline & & Validation Set & McNemar Exact Test 1-sided $p$-value \\
\hline Cutoffs & DAS + N3AP + CA125 & CA125 & 0.02 \\
Sensivitiy @ 99\% Specificity & 73.7 & 62.2 & 0.37 \\
Sensivitiy @ 98.5\% Specificity & 78.6 & 81.9 & 0.38 \\
\hline Sensivitiy @ 97\% Specificity & 83.6 & 86.8 & \\
\hline
\end{tabular}

Table A7. Classification performance of plasma polyamines in distinguishing serous or non-serous cases from controls in the Validation Set.

\begin{tabular}{|c|c|c|c|c|c|c|c|c|c|c|c|c|c|c|c|}
\hline \multirow[b]{2}{*}{ Metabolite } & \multicolumn{5}{|c|}{ All Cases $(n=61)$ vs. Controls $(n=71)$} & \multicolumn{5}{|c|}{ Serous Cases $(n=28)$ vs. Controls $(n=71)$} & \multicolumn{5}{|c|}{$\begin{array}{l}\text { Non-Serous Cases }(n=33) \text { vs. Controls } \\
\qquad(n=71)\end{array}$} \\
\hline & AUC & $\begin{array}{l}95 \% \\
\text { CI }\end{array}$ & $p+$ & $\begin{array}{l}\text { Sens @ } \\
95 \% \text { Spec }\end{array}$ & $\begin{array}{l}\text { Spec @ } \\
95 \% \text { Sens }\end{array}$ & AUC & $\begin{array}{l}95 \% \\
\mathrm{CI}\end{array}$ & $p+$ & $\begin{array}{l}\text { Sens @ } \\
95 \% \text { Spec }\end{array}$ & $\begin{array}{l}\text { Spec@ } \\
95 \% \text { Sens }\end{array}$ & AUC & $\begin{array}{l}95 \% \\
\mathrm{CI}\end{array}$ & $p+$ & $\begin{array}{l}\text { Sens @ } \\
95 \% \text { Spec }\end{array}$ & $\begin{array}{l}\text { Spec@ } \\
95 \% \text { Sens }\end{array}$ \\
\hline Diacetylspermine & 0.84 & $\begin{array}{l}0.77- \\
0.91\end{array}$ & $<0.001$ & 52.5 & 33.8 & 0.84 & $\begin{array}{l}0.75- \\
0.93\end{array}$ & $<0.001$ & 46.4 & 33.8 & 0.84 & $\begin{array}{l}0.75- \\
0.92\end{array}$ & $<0.001$ & 57.6 & 23.9 \\
\hline Diacetylspermidine & 0.57 & $\begin{array}{l}0.47- \\
0.67\end{array}$ & 0.18 & 13.1 & 1.4 & 0.56 & $\begin{array}{l}0.42- \\
0.70\end{array}$ & 0.33 & 10.7 & 0 & 0.57 & $\begin{array}{l}0.44- \\
0.70\end{array}$ & 0.25 & 15.2 & 1.4 \\
\hline Acetylspermidine & 0.67 & $\begin{array}{l}0.57- \\
0.77\end{array}$ & $<0.001$ & 27.9 & 2.8 & 0.64 & $\begin{array}{l}0.50- \\
0.78\end{array}$ & 0.03 & 25.0 & 2.8 & 0.69 & $\begin{array}{l}0.57- \\
0.81\end{array}$ & 0.002 & 30.3 & 2.8 \\
\hline N3AP & 0.59 & $\begin{array}{l}0.49- \\
0.69\end{array}$ & 0.08 & 18.0 & 4.2 & 0.58 & $\begin{array}{l}0.44- \\
0.72\end{array}$ & 0.21 & 17.9 & 4.2 & 0.59 & $\begin{array}{l}0.46- \\
0.72\end{array}$ & 0.12 & 18.2 & 2.8 \\
\hline
\end{tabular}


Test Set

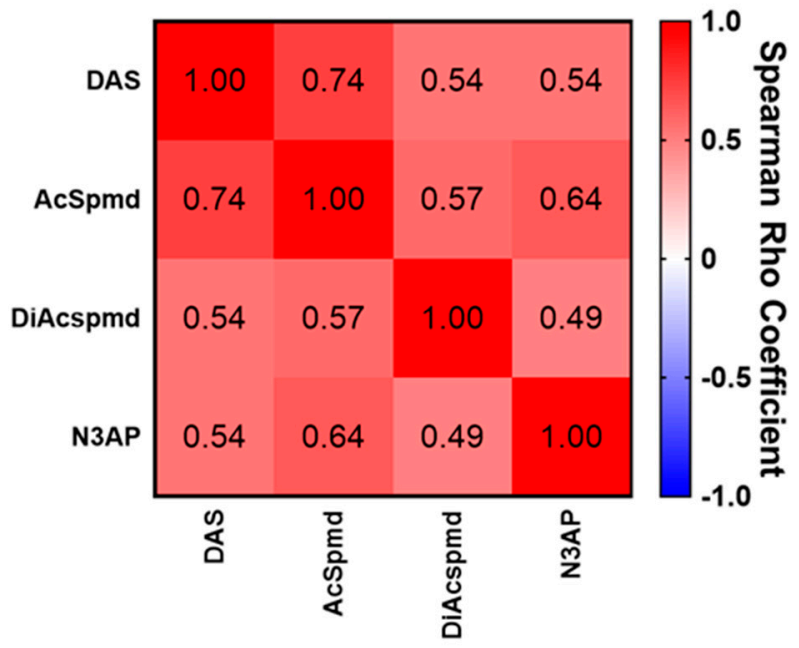

\section{Validation Set}

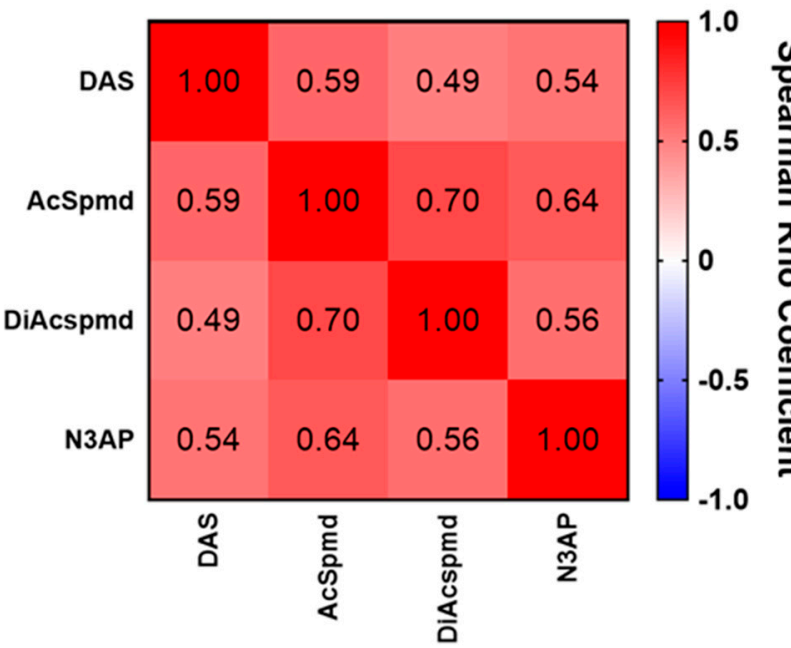

Figure A1. Spearman correlation matrix for polyamines. Heatmaps depicting spearman correlation coefficients amongst the 4 measured polyamines in the Test Set (left panel) and Validation Set (right panel). Embedded values represent Spearman correlation coefficients. All cases and controls corresponding to the respective test set were included in the analyses. Abbrev. DAS- diacetylspermine; AcSpmd- acetylspermidine; DiAcspmd- diacetylspermidine; N3AP- N-(3acetamidopropyl)pyrrolidin-2-one.

Diacetylspermine

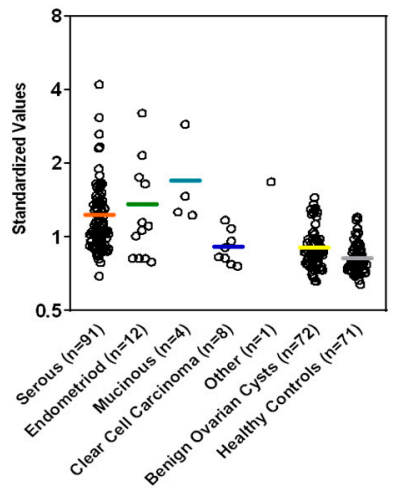

Diacetylspermidine

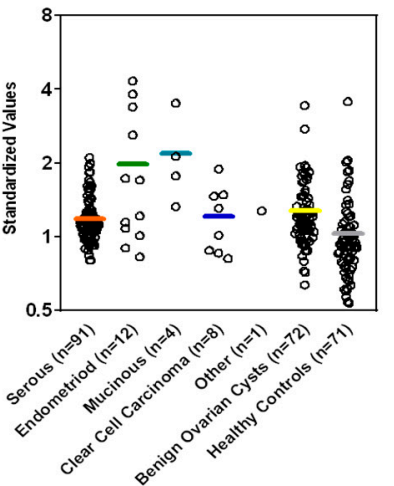

Acetylspermidine

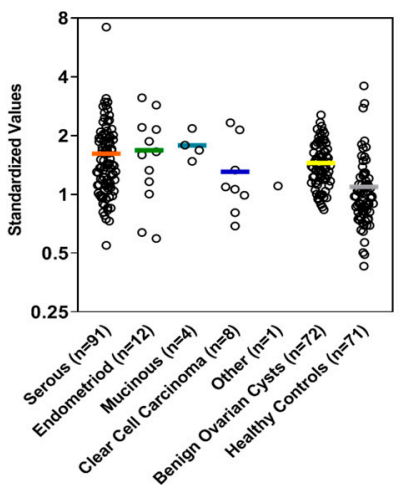

N3AP

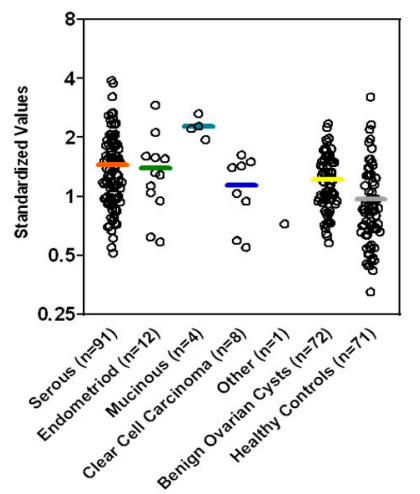

Figure A2. Plasma levels of polyamines in cases stratified by histology and controls in the Test Set.

Diacetylspermine

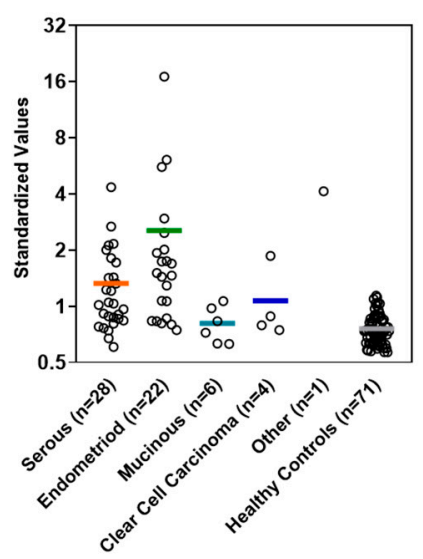

Diacetylspermidine

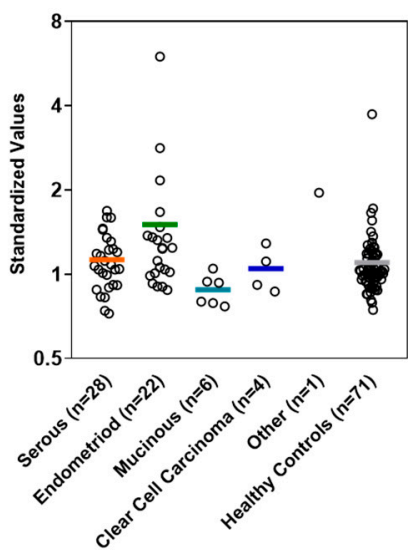

Acetylspermidine

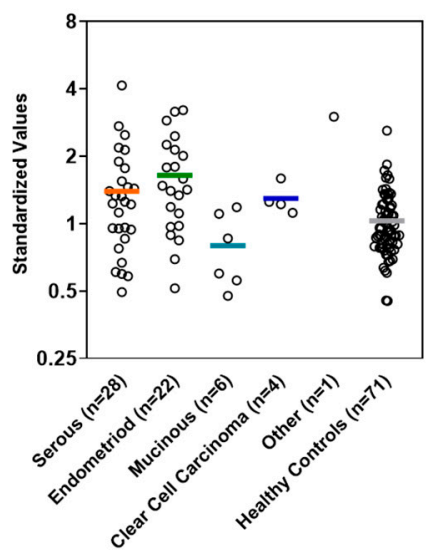

N3AP

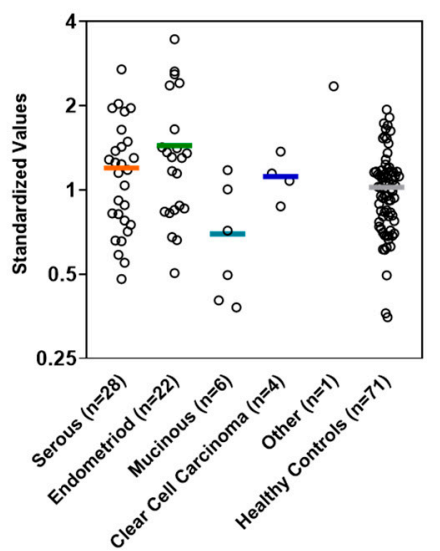

Figure A3. Plasma levels of polyamines in cases stratified by histology and controls in the Validation Set. 


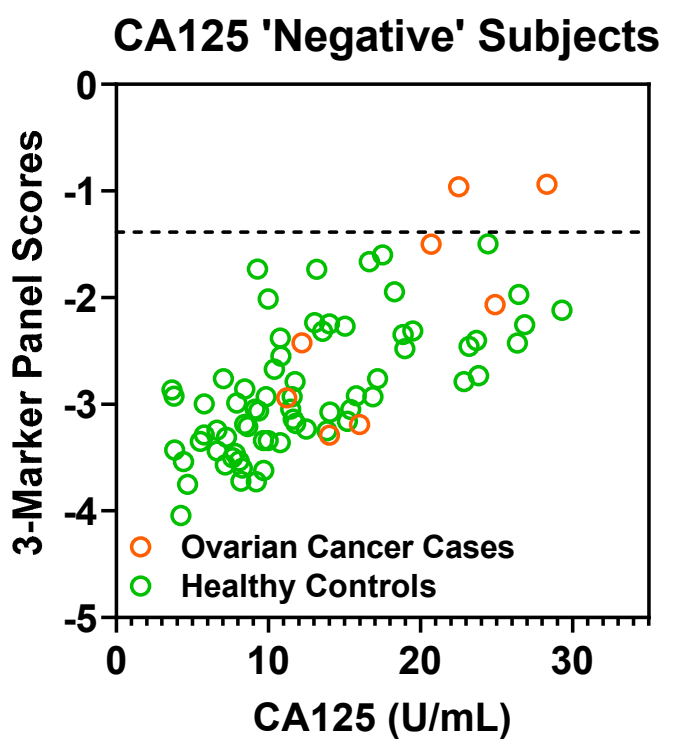

Figure A4. Scatter plot of depicting 3-marker panel scores (Y-axis) and CA125 values (X-axis) in CA125 'negative' (defined as $\leq 35 \mathrm{U} / \mathrm{mL}$ ) subjects in the Validation Set. Dashed lines represent $100 \%$ specificity cutoff.

\section{References}

1. Badgwell, D.; Bast, R.C., Jr. Early detection of ovarian cancer. Dis. Markers 2007, 23, 397-410. [CrossRef]

2. Siegel, R.L.; Miller, K.D.; Jemal, A. Cancer Statistics, 2017. CA Cancer J. Clin. 2017, 67, 7-30. [CrossRef] [PubMed]

3. Fortner, R.T.; Schock, H.; Le Cornet, C.; Husing, A.; Vitonis, A.F.; Johnson, T.S.; Fichorova, R.N.; Fashemi, T.; Yamamoto, H.S.; Tjonneland, A.; et al. Ovarian cancer early detection by circulating CA125 in the context of anti-CA125 autoantibody levels: Results from the EPIC cohort. Int. J. Cancer 2018, 142, 1355-1360. [CrossRef]

4. Lu, K.H.; Skates, S.; Hernandez, M.A.; Bedi, D.; Bevers, T.; Leeds, L.; Moore, R.; Granai, C.; Harris, S.; Newland, W.; et al. A 2-stage ovarian cancer screening strategy using the Risk of Ovarian Cancer Algorithm (ROCA) identifies early-stage incident cancers and demonstrates high positive predictive value. Cancer 2013, 119, 3454-3461. [CrossRef] [PubMed]

5. $\quad$ Bast, R.C., Jr.; Xu, F.J.; Yu, Y.H.; Barnhill, S.; Zhang, Z.; Mills, G.B. CA 125: The past and the future. Int. J. Biol. Markers 1998, 13, 179-187. [CrossRef] [PubMed]

6. The Cancer Genome Atlas Network. Comprehensive molecular portraits of human breast tumours. Nature 2012, 490, 61-70. [CrossRef] [PubMed]

7. Li, C.; Bonazzoli, E.; Bellone, S.; Choi, J.; Dong, W.; Menderes, G.; Altwerger, G.; Han, C.; Manzano, A.; Bianchi, A.; et al. Mutational landscape of primary, metastatic, and recurrent ovarian cancer reveals c-MYC gains as potential target for BET inhibitors. Proc. Natl. Acad. Sci. USA 2019, 116, 619-624. [CrossRef]

8. Chen, C.H.; Shen, J.; Lee, W.J.; Chow, S.N. Overexpression of cyclin D1 and c-Myc gene products in human primary epithelial ovarian cancer. Int. J. Gynecol. Cancer Off. J. Int. Gynecol. Cancer Soc. 2005, 15, 878-883. [CrossRef]

9. Papp, E.; Hallberg, D.; Konecny, G.E.; Bruhm, D.C.; Adleff, V.; Noë, M.; Kagiampakis, I.; Palsgrove, D.; Conklin, D.; Kinose, Y.; et al. Integrated Genomic, Epigenomic, and Expression Analyses of Ovarian Cancer Cell Lines. Cell Rep. 2018, 25, $2617-2633$. [CrossRef] [PubMed]

10. Fahrmann, J.F.; Vykoukal, J.; Fleury, A.; Tripathi, S.; Dennison, J.B.; Murage, E.; Wang, P.; Yu, C.Y.; Capello, M.; Creighton, C.J.; et al. Association between plasma diacetylspermine and tumor spermine synthase with outcome in triple negative breast cancer. J. Natl. Cancer Inst. 2019. [CrossRef] [PubMed]

11. Fahrmann, J.F.; Bantis, L.E.; Capello, M.; Scelo, G.; Dennison, J.B.; Patel, N.; Murage, E.; Vykoukal, J.; Kundnani, D.L.; Foretova, L.; et al. A Plasma-Derived Protein-Metabolite Multiplexed Panel for Early-Stage Pancreatic Cancer. J. Natl. Cancer Inst. 2018, 111, 372-379. [CrossRef]

12. Tibshirani, R. Regression shrinkage and selection via the lasso. J. R. Stat. Soc. Ser. B Methodol. 1996, 58, 267-288. [CrossRef]

13. Walker, G.; Jack Shostak. Common Statistical Methods for Clinical Research with SAS Examples; SAS Institute: Cary, NC, USA, 2010.

14. Breslow, N.E.; Nicholas, E. Day, and Elisabeth Heseltine. In Statistical Methods in Cancer Research; IARC: Lyon, France, 1980; Volume 1.

15. Dorigo, O.; Berek, J.S. Personalizing CA125 Levels for Ovarian Cancer Screening. Cancer Prev. Res. 2011, 4, 1356-1359. [CrossRef]

16. Peres, L.C.; Cushing-Haugen, K.L.; Köbel, M.; Harris, H.R.; Berchuck, A.; Rossing, M.A.; Schildkraut, J.M.; Doherty, J.A. Invasive Epithelial Ovarian Cancer Survival by Histotype and Disease Stage. J. Natl. Cancer Inst. 2019, 111, 60-68. [CrossRef]

17. Integrated genomic analyses of ovarian carcinoma. Nature 2011, 474, 609-615. [CrossRef] 
18. Darcy, K.M.; Brady, W.E.; Blancato, J.K.; Dickson, R.B.; Hoskins, W.J.; McGuire, W.P.; Birrer, M.J. Prognostic relevance of c-MYC gene amplification and polysomy for chromosome 8 in suboptimally-resected, advanced stage epithelial ovarian cancers: A Gynecologic Oncology Group study. Gynecol. Oncol. 2009, 114, 472-479. [CrossRef]

19. Wang, Z.R.; Liu, W.; Smith, S.T.; Parrish, R.S.; Young, S.R. c-myc and chromosome 8 centromere studies of ovarian cancer by interphase FISH. Exp. Mol. Pathol. 1999, 66, 140-148. [CrossRef] [PubMed]

20. Wu, R.; Lin, L.; Beer, D.G.; Ellenson, L.H.; Lamb, B.J.; Rouillard, J.M.; Kuick, R.; Hanash, S.; Schwartz, D.R.; Fearon, E.R.; et al. Amplification and overexpression of the L-MYC proto-oncogene in ovarian carcinomas. Am. J. Pathol. 2003, 162, 1603-1610. [CrossRef]

21. Helland, Å.; Anglesio, M.S.; George, J.; Cowin, P.A.; Johnstone, C.N.; House, C.M.; Sheppard, K.E.; Etemadmoghadam, D.; Melnyk, N.; Rustgi, A.K.; et al. Deregulation of MYCN, LIN28B and LET7 in a molecular subtype of aggressive high-grade serous ovarian cancers. PLoS ONE 2011, 6, e18064. [CrossRef]

22. Ohshima, K.; Hatakeyama, K.; Nagashima, T.; Watanabe, Y.; Kanto, K.; Doi, Y.; Ide, T.; Shimoda, Y.; Tanabe, T.; Ohnami, S.; et al. Integrated analysis of gene expression and copy number identified potential cancer driver genes with amplification-dependent overexpression in 1,454 solid tumors. Sci. Rep. 2017, 7, 641. [CrossRef]

23. Bachmann, A.S.; Geerts, D. Polyamine synthesis as a target of MYC oncogenes. J. Biol. Chem. 2018, 293, 18757-18769. [CrossRef] [PubMed]

24. Funakoshi-Tago, M.; Sumi, K.; Kasahara, T.; Tago, K. Critical roles of Myc-ODC axis in the cellular transformation induced by myeloproliferative neoplasm-associated JAK2 V617F mutant. PLoS ONE 2013, 8, e52844. [CrossRef] [PubMed]

25. Hogarty, M.D.; Norris, M.D.; Davis, K.; Liu, X.; Evageliou, N.F.; Hayes, C.S.; Pawel, B.; Guo, R.; Zhao, H.; Sekyere, E.; et al. ODC1 is a critical determinant of MYCN oncogenesis and a therapeutic target in neuroblastoma. Cancer Res. 2008, 68, 9735-9745. [CrossRef] [PubMed]

26. Niemi, R.J.; Roine, A.N.; Hakkinen, M.R.; Kumpulainen, P.S.; Keinanen, T.A.; Vepsalainen, J.J.; Lehtimaki, T.; Oksala, N.K.; Maenpaa, J.U. Urinary Polyamines as Biomarkers for Ovarian Cancer. Int. J. Gynecol. Cancer Off. J. Int. Gynecol. Cancer Soc. 2017, 27, 1360-1366. [CrossRef] [PubMed]

27. Cheng, X.; Zhang, L.; Chen, Y.; Qing, C. Circulating cell-free DNA and circulating tumor cells, the "liquid biopsies" in ovarian cancer. J. Ovarian Res. 2017, 10, 75. [CrossRef]

28. Buas, M.F.; Gu, H.; Djukovic, D.; Zhu, J.; Drescher, C.W.; Urban, N.; Raftery, D.; Li, C.I. Identification of novel candidate plasma metabolite biomarkers for distinguishing serous ovarian carcinoma and benign serous ovarian tumors. Gynecol. Oncol. 2016, 140, 138-144. [CrossRef] [PubMed] 